\title{
Time-Varying Bond Market Integration in EMU
}

\author{
Priyanshi Gupta \\ University of Delhi, New Delhi, India \\ Sanjay Sehgal \\ University of Delhi, New Delhi, India \\ Florent Deisting \\ Groupe ESC Pau, Pau, France
}

\begin{abstract}
We examine the level and progress of bond market integration amongst the eleven Economic and Monetary Union countries with active bond markets, over normal and crisis periods. The study covers data from January 2002 up to March 2014. We employ seven indicators for assessing integration, namely beta convergence, sigma convergence, variance ratio, Asymmetric Dynamic Conditional Correlation, dynamic co-integration, market synchronisation, and common factors approach. The results suggest that there is no heterogeneity in the integration process of large-sized economies and medium-sized economies, thereby restricting portfolio diversification potential. Further, bond market integration in the Economic and Monetary Union deteriorated during the crisis period, especially during the European debt crisis, with the economies of Greece, Ireland, Italy, Portugal, and Spain being the worst affected. We observe that bond markets take a lead in information linkages vis-à-vis stock markets, and hence should get precedence in policy intervention relating to market integration, development, and crisis management.
\end{abstract}

\footnotetext{
* Corresponding Author: Priyanshi Gupta; Department of Financial Studies, University of Delhi, South Campus, Benito Juarez Road, New Delhi, 110021, India; Tel: +91 8879252473, E-mail: priyanshiguptadu@gmail.com.

Co-author: Sanjay Sehgal; Department of Financial Studies, University of Delhi, South Campus, Benito Juarez Road, New Delhi, 110021, India; Tel: +91 9891199840, E-mail: sanjayfin15@yahoo.co.in,

Florent Deisting; Group ESC Pau, Département Acadadémique Finance-Economie, 3 Rue Saint-John Perse, 64000 Pau, France; Tel: +33 (0)0559923344, E-mail: florent.deisting@esc-pau.fr.
} 
JEL Classifications: C22, E44, F36, G14, G15

Keywords: Bond Market Linkages, EMU Countries, Global Financial Crisis, European Debt Crisis, Time-varying Financial Integration.

\section{Introduction}

As the recent financial crisis developed from a global banking crisis in the summer of 2007 to the European sovereign debt crisis in the late 2009, there were intense debates on the probable exit policies of members of the European Economic and Monetary Union (EMU) (Bootle et al. 2012), implying the possible disintegration of the union. The sovereign debt markets of the EMU members remained at the centre of the European Debt Crisis (EDC). The crisis was attributed to weak fundamentals, especially the challenges faced by the GIIPS ${ }^{1}$ countries in refinancing their sovereign debt, followed by the spread of crisis through contagion. In this light, it becomes important to gauge the two-way relationship between sovereign bond market integration and crisis; that is, if integration led the way to contagion through enhanced systemic risk resulting in a panEMU crisis, and/or if the crisis led to disintegration.

Given the wide, multidimensional nature of the concept of financial integration, drawing conclusions based on a single indicator of integration is not advisable. Thus, this paper employs seven different indicators of integration, each with a different focus: i) Beta Convergence (measures the speed of convergence); ii) Sigma Convergence (measures the cross-sectional dispersion); iii) Variance Ratio (measures the variance from common source); iv) Asymmetric Dynamic Conditional Correlation (measures time-varying correlation); v) Dynamic Co-integration (assesses time-varying, longrun relationship); vi) Market Synchronisation Measure (tests the presence of a similar economic regime); and vii) Common Factors Approach (measures the variance caused by pre-defined economic common factors and statistical common factors derived from Principal Component analysis). The analysis enables us to develop a broad and exhaustive perspective about the progress of integration in the regional bond markets. Furthermore, as integration tends to change in response to economic and financial

${ }^{1}$ GIIPS is used to represent the five troubled European economies, i.e., Greece, Ireland, Italy, Portugal, and Spain. 
conditions, all the indicators used in this study are time varying to capture the dynamics of integration over time.

This study also focuses on the inter-financial market integration between the stock and government bond markets of the sample countries. This shall facilitate in inferring the order in which integration progresses from one financial market to another, as it is important for the policy-makers from the point of implementing integration related policies across different financial sectors.

The study covers eleven EMU member countries, which are classified into two groups, A and B, based on their economic size measured by Gross Domestic Product (GDP). This is done in order to test the generally held view that high income economies are more likely to integrate with other economies owing to higher cross-border capital flows as they typically have more stable macroeconomic policies, lower credit and liquidity risk, better financial and institutional architecture, and deeper markets. The sample period for the study starts with the introduction of the euro currency. The total period is divided into three non-overlapping sub-periods covering Pre-crisis Normal Period, Global Financial Crisis (GFC), along with the ensuing EDC to facilitate the analysis of bond market integration across different economic regimes.

In Europe, the bond markets account for two-thirds of the total amount of securities outstanding in the capital market, of which approximately $60 \%$ is government bond debt. ${ }^{2}$ Sovereign bond markets play several critical roles such as instrument for investment, source of finance for government deficits, carrier for monetary policy, and instrument in macroeconomic analysis and portfolio diversification for global portfolio managers and investors. Given their important role, the policy-makers have undertaken several measures for the development and integration of bond markets in Europe, such as synthetic Credit Transfer Instruments, regularly improved versions of the TransEuropean Automated Real-time Gross Settlement Express Transfer system (TARGET), and Covered Bond label that was operationalised in January 2013. In the aftermath of crisis, any further policy initiatives for the development and integration of the bond markets should be preceded by a sound measurement of the extent of bond market integration in both normal and crisis periods. This remains the primary motivation for our study.

Our empirical results reveal that bond market integration is not affected by the size of the economy, as the degree of integration does not vary between Groups A and B.

\footnotetext{
2 AFME. Overview -The European and Global Bond Markets. Accessed November 2014. http://www.investinginbondseurope.org/ pages/learnaboutbonds.aspx?folder_id=464.
} 
However, there is variation in the integration between the GIIPS group and non-GIIPS group. ${ }^{3}$ It is found that the integration deteriorated during the crisis period across all economies. In addition, the analysis shows that bond markets take a lead in information linkages vis-à-vis stock markets. These results have important policy implications.

The paper is organised as follows. Section II provides a brief review of literature. Section III covers a discussion about different types of indicators of financial integration along with the econometric methodologies for their estimation. The data and their sources are described in Section IV. The empirical results are presented and analysed in Section V. Information linkages between EMU bond and stock markets with relevant implications are discussed in Section VI. Conclusion and policy observations are provided in the final section.

\section{Literature Review}

While the studies on financial integration form an integral part of international finance, the majority of the academic focus remains restricted to stock markets. The introduction of euro has stimulated interest on the issue of whether it has led to a greater integration of the EMU's bond markets. To this end, Cappiello et al. (2006) propose two methodologies to measure integration: time-varying (GARCH) correlation and regression quantile-based co-dependence measure. They conclude that the introduction of euro emerged as a major factor in fostering integration in the bond markets of both small and large euro area economies. Similarly, Skintzi and Refenes (2006) report that for most European bond markets, the introduction of the euro has strengthened the volatility spill over effects and the cross-correlations which were measured using the Dynamic Conditional Correlation (DCC) framework. Kim et al. (2006a) employ a set of three complementary techniques: dynamic co-integration, Haldane and Hall method, and time varying correlations. They conclude that while the bond market integration was strong for the economies of EMU, it was weak and stable for other nonEMU economies including the UK. Further, in a study on the dynamic inter-financial integration between the stock and government bond markets in Europe, Kim et al. (2006b)

\footnotetext{
${ }^{3}$ It is noteworthy that the GIIPS economies of Greece, Ireland, Italy, Portugal, and Spain have a rating lower than AA based on the ratings of S\&P, Fitch and Moody's, while the remaining sample economies have a higher rating.
} 
conclude that the reduction in currency risk has strengthened both intra stock-bond and inter stock-bond integration. However, bond market shocks are observed to have more influence than stock market shocks. Using Bekaert and Harvey's CAPM-based model (1995), Lamedica \& Reno (2007) report that the level of integration increased after the introduction of the euro; however, these bond markets were still partially integrated. Employing the same model, Abad et al. (2010) conclude that while the non-EMU countries are more influenced by world risk factors, the EMU members are influenced by Eurozone risk factors; however, they are only partially integrated. Georgoutsos and Migiakis (2010) employ Markovian regime shifting effects to empirically identify the states of higher and lower interactions after the monetary unification in Europe. They find that the deterministic processes of the cross-countries bond spreads are more similar under low volatility conditions, indicating a positive relation in the stability between financial markets and financial integration.

There is only limited literature that studies the impact of crisis on bond market integration, majority of which focuses only on GFC, while the impact of EDC is not adequately analysed. Abad et al. (2011) examine the time-varying nature of the Eurozone bond market integration using Bekaert and Harvey's CAPM-based model (1995). They conclude that the integration declined in all sample countries after the onset of the financial crisis in August 2007. The time-varying nature of bond market integration is also shown by Cipollini et al. (2013), who used panel regression to investigate the impact of the EMU and the recent crisis on the European sovereign debt market integration. The results show a one-off positive impact of euro on integration; however, the recent crisis is shown to lead to segmentation amongst the debt markets. The adverse impact of crisis on integration is also reported by Pozzi and Wolswijk (2012). The results of the International CAPM (ICAPM) model, estimated using space state methods, show that while country-specific exposure to common international risk factor has equalised the bond markets of sample European economies, the idiosyncratic risk factor re-emerged during the global financial crisis. Christiansen (2014) measures dynamic integration with the explanatory power of the European factor portfolios of the individual bond markets in each individual country. She found that the EMU countries are more integrated than the non-EMU countries. Further, the integration of EMU bond markets was affected by lower credit ratings and the crisis period.

While the extant body of work is highly relevant to the area of bond market integration, there still exist important gaps that our study aims to fill: i) there is a lack of research on how the progress of integration varies in normal vis-à-vis crisis periods. In 
this paper, we split the sample period into three sub-periods; that is, the Normal period, the GFC period, and the EDC period to capture the dynamics of integration; ii) existing studies do not undertake to study variation in the degree of integration across different types of economies. We therefore divide the sample EMU economies into two groups based on the size of the economy; iii) this paper provides a broader view of integration as it employs seven different indicators to measure different dimensions of bond market integration in the region; iv) we also study the inter-financial market integration between stock and government bond markets, which is very important from the perspective of policy creation and implementation.

\section{Data and Descriptive Statistics}

\section{A. Data}

Our dataset is comprised of eleven euro area countries; Austria, Belgium, Finland, France, Germany, Greece, Ireland, Italy, Netherlands, Portugal, and Spain. The choice of the sample set is constrained by the limited data availability because of negligible bond markets in other EMU countries. We retrieve daily Bloomberg EFFAS' 7-10 year government bond total returns indices ${ }^{4}$ for individual countries, as well as for the euro bloc, ${ }^{5}$ to study the integration of long-term bond markets in the EMU. The continuously compounded bond return series is measured as the first natural log differences of the total returns indices. The return series is denominated in US dollars. It is generally maintained that large economies exhibit higher financial integration owing to better macroeconomic and external trade conditions. In order to check this premise, we classify the sample EMU countries into two groups based on the size of the economy measured as GDP. We have grouped Belgium, France, Germany, Italy, Netherlands, and Spain under Group A. These countries represent the larger economies of the EMU, with liquid and largest government debt markets. Austria, Finland, Greece, Ireland, and Portugal are classified

\footnotetext{
${ }^{4}$ The Total Returns Bond Indices represent the total return (including reinvested coupon payments) to investors from a representative portfolio of government bonds.

${ }^{5}$ The Bloomberg/EFFAS Euro Govt. 7-10y Total Returns Index is employed to capture the bond market information for the entire Eurozone area.
} 
under Group B. Table 1 provides the information regarding the size of economies, the date of EMU membership, and the size of government debt (total outstanding gross debt as a percentage of GDP) for the sample countries to provide a relative picture of size and level of activity in these markets. The US is included as a proxy for global factor as in prior research (Baele et al. 2004, Bartram et al. 2007).

Table 1. Sample set countries' details

\begin{tabular}{|c|c|c|c|c|c|}
\hline \multirow{3}{*}{ Group } & Country & $\begin{array}{c}\text { GDP 2012 } \\
\text { (millions of euro) }\end{array}$ & $\begin{array}{c}\text { Year of } \\
\text { joining EMU }\end{array}$ & $\begin{array}{c}\text { Symbol } \\
\text { used }\end{array}$ & $\begin{array}{c}\text { Size of government } \\
\text { debt outstanding } \\
\text { (as a percentage of GDP) }\end{array}$ \\
\hline \multirow{5}{*}{ Group A } & Germany & $2,643,900$ & 1999 & GER & 81.9 \\
\cline { 2 - 7 } & France & $2,029,877$ & 1999 & FRC & 90.2 \\
\cline { 2 - 6 } & Italy & $1,565,916$ & 1999 & ITA & 127 \\
\cline { 2 - 6 } & Spain & $1,049,525$ & 1999 & SPN & 84.2 \\
\cline { 2 - 6 } & Netherlands & 600,638 & 1999 & NET & 71.2 \\
\cline { 2 - 6 } & Belgium & 376,840 & 1999 & BEL & 99.6 \\
\hline \multirow{5}{*}{ Group B } & Austria & 309,900 & 1999 & AUS & 73.4 \\
\cline { 2 - 6 } & Freece & 193,749 & 2001 & GRC & 156.9 \\
\cline { 2 - 6 } & Finland & 194,469 & 1999 & FIN & 53 \\
\cline { 2 - 6 } & Portugal & 165,409 & 1999 & POR & 123.6 \\
\cline { 2 - 6 } & Ireland & 163,595 & 1999 & IRE & 117.6 \\
\hline
\end{tabular}

(Source) ${ }^{a}$ International Monetary Fund, World Economic Outlook Database, April 2013 edition. ${ }^{b}$ As at the end of 2012, sourced from Eurostat.

The sample period for this study starts from January 1, 2002 when euro currency entered into circulation, and stretches up to March 10, 2014. However, for Greece, the sample period is limited only up to March 29, 2012 due to the unavailability of timeseries data on daily frequency. The non-trading days vary across the sample countries with different holidays; hence, to avoid complications, the value of the corresponding index on such days is assumed to remain constant and equal to its closing value on the last trading day before the holiday.

In order to study the dynamics of integration in normal vis-à-vis crisis period, we 
break the sample period into three sub-periods. The first sub-sample covers the period from January 1, 2002 to August 8, 2007, which is the Normal period. The crisis period starts from August 9, 2007 (Angelini et al. 2011, Asongu 2012). ${ }^{6}$ The crisis sub-period is further split into two sub-periods, which are the Global Financial Crisis (GFC) period from August 9, 2007 to October 18, 2009 and the Eurozone Debt Crisis (EDC) period, which is October 19, 2009 onwards (Ahmad et al. 2013) when the announcement of a financially distressed Greece triggered panic amongst investors. This facilitates the separate analysis of the EDC as this study deals with EMU.

\section{B. Descriptive statistics}

The descriptive statistics show that there has been a substantial increase in the variance during the GFC period compared to the Normal period, while during the EDC period, all countries exhibited a fall in standard deviation, except in GIIPS economies, among whom, Greece and Portugal show notable increase in variance. The bond returns for all sample countries remained positively skewed except Greece during GFC and Portugal during EDC. The distributions of returns for the countries are statistically nonnormal as they exhibit leptokurtosis and statistically significant Jarque-Bera multiplier across all sub-periods. Ljung-Box statistic up to 12 orders in levels $(Q 12)$ and square of returns $\left(Q^{2}\right)$ were also estimated. The results for $Q$-statistics in levels indicate the absence of serial correlation during all periods for all sample countries except for Ireland and Portugal during the crisis. However, the presence of autoregressive conditional heteroscedasticity cannot be rejected given the significant statistics for $Q^{2}$ and ARCH tests for all the sample countries, except for Greece, which does not exhibit Autoregressive Conditional Heteroskedasticity (ARCH) effects during EDC. As a pre-cursor to the time-series analysis, we conducted the Augmented Dickey Fuller (ADF) test to test for unit root. In addition, Perron (1997) test was employed to identify structural breaks as the European markets had undergone multiple structural changes over the period. Perron (1997) provides for structural breaks both in the null as well as

\footnotetext{
${ }^{6}$ Although subprime mortgage lenders started to report losses in February 2007 (Cecchetti 2009), August 9, 2007 is considered as the advent of financial market crisis when BNP Paribas ceased activity in three hedge funds which was followed by sharp rise in cost of credit. This date is in agreement with The Guardian's timeline of financial crisis (http://www.theguardian.com/business/2012/ aug/07/credit-crunch-boom-bust-timeline), the BBC Timeline (http://news.bbc.co.uk/2/hi/business/7521250.stm) as well as Bank of International Settlements (BIS, 79 ${ }^{\text {th }}$ Annual Report, retrieved from http://www.bis.org/publ/arpdf/ar2009e2.pdf).

${ }^{7}$ The results on descriptive statistics, normality and Ljung-Box tests are Shown in Appendix 1.
} 
alternative hypothesis. The test considers three alternative models that allow a break respectively in the intercept, the slope, and in both slope and intercept. The test statistics for both the tests indicate that all the total returns series are I (1). Second, we observed that the breakpoints, as identified by the Perron (1997) test, vary across markets and estimated models. ${ }^{8}$

\section{Methodological Issues}

In this section, we describe the methodologies of constructing different indicators employed to measure multiple dimensions of bond market integration in the EMU. As the tests established breaks in the time series, all the measures of integration in this study incorporate rolling estimation to capture the time varying dynamics of bond market integration.

\section{A. Beta convergence}

Barro and Sala-I-Martin (1992) and Mankiw et al. (1992) initiated the concept of beta convergence to measure the convergence of the growth levels of the economies. The negative sign of beta coefficient indicates the mean reversion of returns and hence the presence of convergence. The absolute value of Beta indicates the speed at which the bond returns of the country's national index converges towards the returns on the regional index. Beta convergence is quantified by estimating the following regression:

$$
\Delta E R_{i, t}=\alpha_{i}+\beta_{i, t} E R_{i, t-1}+\sum_{l=1}^{L} \gamma_{l} \Delta E R_{i, t-1}+\varepsilon_{i, t}
$$

Here, $E R_{i, t}$ represents the return differential between country $i$ 's index and the benchmark index at time $t . \beta_{i, t}$ is the convergence coefficient and provides the estimate of the speed of convergence. The lag length $l$ is determined using the Schwarz Information Criteria (SIC). Beta coefficient is made time-varying using the rolling regression

\footnotetext{
${ }^{8}$ For the brevity of space, the results are not provided here. The results are shown in Appendix 2.
} 
technique with a fixed window of 65 trading days, which approximates to one quarter. Under the null of no convergence, $\beta$ is equal to zero. The larger the beta is in absolute value, the faster the convergence is.

\section{B. Sigma convergence}

Sigma Convergence forms another pillar of Convergence Growth literature. Sigma Convergence assesses the extent to which markets are already integrated. It is an indicator of cross-sectional dispersion of returns against a benchmark. This measure is based on the law of one price, which states that if the economies are to be integrated, returns on assets with identical structures should be equalised across these economies.

The value of sigma is estimated as:

$$
\sigma_{t}=\sqrt{N^{-1} \sum_{i=1}^{N}\left[R_{i, t}-R_{b, t}\right]^{2}}
$$

Here, $R_{i, t}$ and $R_{b, t}$ are the returns on bond indices of country $i$ and the benchmark index, respectively. $N$ is the number of economies in analysis. The value of sigma is always positive. We undertake estimation over the rolling samples of 65 days each for every sample country to appraise the progress of cross-sectional convergence over time. A high value of sigma indicates a very low level of integration whereas sigma equals zero is a sign of full integration.

\section{Variance ratio}

Jorion and Schwartz (1986) argue that with integration, market index becomes meanvariance efficient and hence only systematic risk relative to the world market enters the pricing of assets. The variance ratio is based on second moments and analyses the crossmarket transmission of news. It examines the significance of common regional/global innovations in explaining the national returns variation. It is a news-based measure, designed to distinguish the information effects from other frictions or barriers (Baele et al. 2004). The returns on the national index of country $i$ are specified as an AR $(p)$ process and $p$, lag length, is selected using SIC. 


$$
r_{i, t}=\alpha_{i}+\sum_{k=1}^{n} \beta r_{i, t-k}+\varepsilon_{i, t}
$$

Here, $r_{i, t}$ is country $i$ 's returns at time $t$. The error term $\varepsilon_{i, t}$ is the unexpected component of return and it captures financial shocks. It can be decomposed into a local shock $\left(e_{i, t}\right)$, reaction to regional news (proxied by the unexpected component of regional bond market return, $\varepsilon_{E M U, t}$ ), and reaction to global innovations (proxied by the unexpected component of world bond market return, $\left.\varepsilon_{U S, t}\right)$.

$$
\varepsilon_{i, t}=\gamma_{1, i, t} \varepsilon_{E M U, t}+\gamma_{2, i, t} \varepsilon_{U S, t}+e_{i, t}
$$

To capture the time-varying impact of cross-market innovations, we used rolling regression with a fixed window of 65 days. The conditional variances in the EMU, US, and country $i$ 's bond markets are assumed to follow the EGARCH $(1,1)$ process. From Equation (4), the total variance of country $i$ can be given by:

$$
\sigma_{i, t}^{2}=\left(\gamma_{1, i, t}\right)^{2} \sigma_{E M U, t}{ }^{2}+\left(\gamma_{2, i, t}\right)^{2} \sigma_{U S, t}{ }^{2}+h_{i, t}
$$

The model assumes that the shocks of country $i$, EMU, and US are uncorrelated with each other. The conditional variances estimated above are employed to obtain regional variance ratio:

$$
\text { Euro Variance Ratio }\left(V R_{i, t}^{E M U}\right)=\frac{\left(\gamma_{1, i, t}\right)^{2} \sigma_{E M U, t}^{2}}{\sigma_{i, t}^{2}}
$$

A variance ratio equal to unity implies full integration wherein only regional news should drive local returns.

\section{Asymmetric dynamic conditional correlation model}

The seminal work of Markowitz (1952), a modern portfolio theory, underlines that not only returns and volatilities are important in the portfolio selection process, but also correlations between assets. Higher correlation implies that markets are integrated through the co-movement of returns, offering similar assets with limited diversification benefits. However, a static measure of correlation is inadequate to measure integration 
across different economic regimes. This paper utilizes the Asymmetric DCC-EGARCH (ADCC-EGARCH) model introduced by Cappiello et al. (2006) which accounts for heteroscedasticity and continuously adjusts for the time varying volatility. ADCC accounts for the asymmetry in correlations that are observed to increase more after a joint negative shock ${ }^{9}$ instead of a positive shock (Baumohl 2013). The Exponential GARCH (EGARCH) model accommodates the asymmetries in conditional variances of returns as the bad news has greater impact rather than the good news (Black 1976, Nelson 1991). The mean equation is specified as an AR (1) process (based on SIC):

$$
r_{i, t}=\alpha_{i}+\sum_{k=1}^{n} \beta_{i, k} r_{i, t-k}+\gamma_{i} r_{U S, t-1}+\varepsilon_{t}
$$

Here, $r_{t}=\left(r_{i, t}, r_{E M U, t}\right)$ and $\varepsilon_{t}=\left(\varepsilon_{i, t}, \varepsilon_{E M U, t}\right), \varepsilon_{t} \mid \beth_{t-1} \sim N\left(0, H_{t}\right)$. The lagged US returns proxy for global effects. The conditional variances of the residuals thus generated are modelled to follow the $\operatorname{EGARCH}(1,1)$ process:

$$
\log \left(h_{i, t}\right)=\omega_{i}+\sum_{j=1}^{p} \psi_{i, j} \log \left(h_{t-j}\right)+\sum_{k=1}^{q}\left[\varphi_{i, k}\left|\frac{\varepsilon_{i, t-k}}{\sqrt{h_{i, t-k}}}\right|+\delta_{i, k} \frac{\varepsilon_{i, t-k}}{\sqrt{h_{i, t-k}}}\right]
$$

Here, $h_{i, t}$ denotes that the time-varying conditional variances of country $i, \omega, \varphi \mathrm{s}$, $\psi \mathrm{s}$, and $\delta \mathrm{s}$ are the parameters to be estimated. The residuals obtained from the mean equation are normalised as $\vartheta_{i, t}=\frac{\varepsilon_{i, t}}{\sqrt{h_{i, t}}}$ which are then utilised to generate a negative residual series to capture the asymmetries: 0

$$
\begin{aligned}
\eta_{i, t} & =\vartheta_{i, t} \text { if } \vartheta_{i, t}>0 \\
& =0 \text { otherwise }
\end{aligned}
$$

The evolution of correlation equation in the ADCC model (Cappiello et al. 2006a) is given by:

$$
Q_{t}=\left(1-\theta_{1}-\theta_{2}\right) \bar{Q}-g \bar{N}+\theta_{1}\left(\varepsilon_{t-1} \varepsilon_{t-1}^{\prime}\right)+\theta_{2} Q_{t-1}+g\left(\eta_{t-1} \eta_{t-1}^{\prime}\right)
$$


Here, $Q_{t}=\left(q_{i j, t}\right)$ is the $(n \times n)$ symmetric positive definite matrix of $\varepsilon_{t}, \bar{Q}=E\left(\varepsilon_{t} \varepsilon_{t}^{\prime}\right)$, $(n \times n)$ is the unconditional correlation matrix of the standardized residuals $\varepsilon_{t}, \bar{N}=E\left(\eta_{t} \eta_{t}^{\prime}\right)$, and the asymmetric term $g$ captures the periods where both markets jointly experience negative shock. The dimension of $\varepsilon_{t}$ is $N$. The scalar parameters $\theta_{1}$ and $\theta_{2}$ are nonnegative and satisfy $\theta_{1}+\theta_{2}<1$. Thus, the evolution process, $Q_{t}$, of the conditional correlation consists of impact, persistence, and asymmetric effect parameters $\theta_{1}, \theta_{2}$, and $g$ respectively. Finally, the dynamic correlation matrix between the two series is given by:

$$
P_{t}=Q_{t}^{*-1} Q_{t} Q_{t}^{*-1}
$$

Here, $Q_{t}^{*}=\left[\sqrt{q_{i i t}}\right]$ is a diagonal matrix with the square root of the $i$ th diagonal elements of $Q_{t}$ as its entries.

\section{E. Dynamic co-integration}

If bond markets are related in the long-run, it has implications for potential long-term gains from diversification. The co-integration analysis tests for the presence of long-run co-movements and common trends amongst bond markets. As the static measure of cointegration provides information only about realized convergence, rolling co-integration analysis with a fixed-length window is more econometrically suited as it accommodates the time varying character of long-run relationships.

We use bivariate co-integration (Johansen 1991) to appraise the long-run relationship between country $i$ 's bond index and the pan-EMU bond index. Let $X_{t}$ denote a vector including the EMU bond market index and country $i$ 's bond market index in log form. If the individual time series are co-integrated, vector $X_{t}$ can be expressed by an Error Correction Model (ECM):

$$
\Delta X_{t}=\sum_{k=1}^{l-1} \tau_{k} \Delta X_{t-k}+\pi \Delta X_{t-k}+\varepsilon_{t}
$$

Matrix $\pi$ can be decomposed as $\alpha \beta^{\prime}$, where matrix $\alpha$ contains the short-run adjustment (Error Correction Term) coefficients to the long-run relationships (the $\beta$ matrix). The rank of $\pi$ determines the $r$ number of co-integrating vectors. 
We utilize trace statistics $\lambda_{t r}$ to test for the null hypothesis of no co-integration as it is considered more preferable over maximum eigen-value $\left(\lambda_{\max }\right)$ statistics (Serletis and King 1997). The rolling co-integration test statistics are calculated setting the fixed window size as 750 trading days, which approximates 3 years, as a wider window is ideal for co-integration analysis (Fung et al. 2008). ${ }^{10}$ The trace statistics obtained from the rolling co-integration tests are scaled by critical values at the $5 \%$ significance level, i.e., 54.079. If the scaled trace statistic value exceeds one, it implies rejection of the null of no co-integration, thus implying the presence of long-run relationship. The Error Correction Term (ECT) enhances this information by describing the responses of variables to the deviations from this long-run equilibrium. The absolute value of the coefficient $\alpha$ of ECT shows the adjustment speed toward long-run equilibrium. A larger $\alpha$ indicates higher speed of adjustment and hence higher convergence. The rolling speed of adjustment coefficients are estimated based on one co-integrating vector. The comparison of coefficients of ECTs for individual countries and Pan-EMU bond index shall help in understanding the lead-lag relationship between the two systems.

\section{F. Market synchronisation}

If at a given point of time, the bond indices of county $i$ and the EMU experience the same regime of the financial market cycle, they are considered as synchronised, thus implying that the markets are integrated. The degree of integration is measured by estimating the correlation between their respective probabilities of being in regime $k$. We define the two regimes of the bond market cycle as bull phase with high average return and bear phase that exhibit a lower average return (Maheu et al. 2010). These phases are identified by employing the Markov Regime Switching Auto Regressive (MRS-AR) model introduced by Hamilton (1989) that offers an endogenous determination of the transition date between regimes whilst, at the same time, accounting for non-linearities in the shock transmission process (Pappas et al. 2013). The model assumes that errors are serially correlated (Hamilton and Gang 1996) and allows for time varying conditional heteroscedasticity as a market migrates from one regime to another.

For this indicator, we use weekly returns, specifically every Wednesday instead of daily returns, as high frequency data may lead to unreliable classification of regimes.

\footnotetext{
${ }^{10}$ The authors would like to thank Dr. Nikolaos Mylonidis for providing us with his Eviews code for rolling co-integration test.
} 
Since MRS-AR model is essentially a non-linear model, we first test for non-linearity using the BDS independence test (Brock et al. 1996) for embedding dimensions from 2 to 6 and for increasing values of $\varepsilon$; that is, $0.5,1.0,1.5$, and 2.0 standard deviations to increase the power of test (Brock et al. 1992).

For the MRS-AR estimation, the mean equation depends on lag states with mean and variance both allowed to switch in states.

$$
r_{t}=\mu\left(s_{t}\right)+\sum_{k=1}^{l} \phi_{k}\left(r_{t-k}-\mu\left(s_{t-k}\right)\right)+\sigma^{2}\left(s_{t}\right) v_{t}
$$

Here, $r_{t}$ is an $\operatorname{AR}(p)$ process, and the unobserved state is governed by the state variables $s_{t}$ and $s_{t-k}$ that take the value of 1 or 2 which corresponds to the bull or bear regime. $l$ is the number of lags which is estimated using the SIC, $\phi_{k}$ is the model parameter, and $v_{t} \sim$ i.i.d $(0,1) . \mu\left(s_{t}\right)$ and $\sigma^{2}\left(s_{t}\right)$ are the mean and variance conditional on the regime at time $t$.

The transition between the states is governed by the first-order Markov assumption that requires that the probability of being in a regime depending on the previous state, so that:

$$
P\left(s_{t}=l \mid s_{t-1}=k\right)=p_{k l}(t)
$$

Here, $k, l=1,2, \ldots, m$; and $\sum_{l=1}^{m} p_{k l}=1$ for all $k, l \in S_{t}$. Therefore, $p_{k l}(t)$ represents the probability of transitioning from regime $i$ in period $t-1$ to regime $l$ in period $t$. The unknown parameters of the model are estimated using the nonlinear filter proposed by Hamilton (1989).

Finally, the probabilities thus generated are transformed using logit transformation to remove 0-1 range restrictions from the values (Ahmad et al. 2014). Let $\widehat{\rho_{i t}}$ be the probability of market $i$ being in bear regime at period $t$.

$$
\operatorname{Logit}\left(\widehat{\rho_{i t}}\right)=\left(\frac{\widehat{\rho_{i t}}}{1-\widehat{\rho_{i t}}}\right)
$$

Financial market integration is measured using Market Synchronisation Correlation, which is quantified as the unconditional correlation between the logits of the regime probabilities of two markets, i.e., country $i$ and the EMU bond index, estimated for the rolling windows of 65 days. 


\section{G. Common factors model}

In case of full integration, only common risks influence the pricing of assets. Under Common Factors Model, the adjusted $R$-square obtained from regression measures the degree of bond market integration as it represents the contribution of common regional factors in explaining the total variance of excess bond returns in country $i$ at a given point of time $t$.

$$
R_{i, t}=\mu_{i}+\beta_{i} R_{E M U, t}+\gamma_{i} R D_{t}+\delta_{i} T S_{t}+\varphi_{i} D S_{t}+\varepsilon_{i, t}
$$

Here, $R_{i, t}$ is the return on the bond index of country $i, R_{E M U, t}$ represents the return on the regional bond index, and $R D_{t}, T S_{t}, D S_{t}$ are the local variables for country $i . R D$ is the Return Differential between regional bond (EFFAS EUR Bond Index) and stock index (EUROSTOXX). TS is the Term Spread quantified as difference between 10-year government bond and 3 month EURIBOR. DS represents Default Spread measured as difference between FTSE Euro Corporate AA bonds and FTSE Euro Corporate BBB bonds. The time-varying nature of integration is captured by using the 65 days rolling window OLS. The variables are appropriately filtered to correct for multicollinearity in order to ensure orthogonality.

We check the robustness of the results by conducting the Principal Components Analysis on the returns of the bond indices in all sample countries along with the EMU. We regress country $i$ 's bond returns on the factors obtained using Principal Component Analysis (PCA). Henceforth, we call these factors as statistical factors. To establish linkages between our economic and statistical factors, we regress the former on the latter. The process will help us in accomplishing factors' identification.

It is worth remarking that given the multiple dimensions of financial integration, the indicators utilized to quantify integration are based on different definitions, assumptions, and methodologies. Hence, the empirical results obtained from them may give a different assessment as to the extent and progress of bond market integration in the region. However, if interpreted with due caution, these indicators shall provide a broad overview of all the dimensions of bond market integration. 


\section{Empirical Results}

Table 2 provides an overview of the indicators describing the dimension of financial integration measured by each of them.

\section{Table 2. Measures of financial integration}

Panel A: Beta Convergence

\begin{tabular}{|c|c|c|c|c|c|c|c|c|c|c|c|}
\hline & \multicolumn{5}{|c|}{ Group A } & \multicolumn{5}{c|}{ Group B } \\
\hline & BEL & FRC & GER & ITA & NET & SPN & AUS & FIN & GRC & IRE & POR \\
\hline Normal Period & -1.241 & -1.249 & -1.078 & -1.093 & -1.594 & -1.349 & -1.862 & -1.418 & -1.270 & -1.230 & -1.320 \\
\hline GFC Period & -0.954 & -1.075 & -0.724 & -1.077 & -1.083 & -0.902 & -1.012 & -1.079 & -0.782 & -0.853 & -0.880 \\
\hline EDC Period & -0.958 & -1.065 & -1.019 & -1.224 & -1.087 & -1.068 & -1.094 & -1.164 & -0.855 & -0.852 & -0.884 \\
\hline
\end{tabular}

Panel B: Sigma Convergence

\begin{tabular}{|c|c|c|c|c|c|c|c|c|c|c|c|}
\hline & \multicolumn{9}{|c|}{ Group A } & \multicolumn{5}{c|}{ Group B } \\
\hline & BEL & FRC & GER & ITA & NET & SPN & AUS & FIN & GRC & IRE & POR \\
\hline Normal Period & 0.000 & 0.000 & 0.000 & 0.000 & 0.000 & 0.000 & 0.000 & 0.000 & 0.000 & 0.001 & 0.000 \\
\hline GFC Period & 0.001 & 0.001 & 0.001 & 0.001 & 0.001 & 0.001 & 0.001 & 0.001 & 0.002 & 0.002 & 0.001 \\
\hline EDC Period & 0.003 & 0.003 & 0.004 & 0.004 & 0.003 & 0.005 & 0.003 & 0.003 & 0.019 & 0.007 & 0.012 \\
\hline
\end{tabular}

Panel C: Variance Ratio

\begin{tabular}{|c|c|c|c|c|c|c|c|c|c|c|c|}
\hline & \multicolumn{5}{|c|}{ Group A } & \multicolumn{5}{c|}{ Group B } \\
\hline & BEL & FRC & GER & ITA & NET & SPN & AUS & FIN & GRC & IRE & POR \\
\hline Normal Period & 0.966 & 0.966 & 0.967 & 0.962 & 0.964 & 0.966 & 0.966 & 0.965 & 0.964 & 0.911 & 0.965 \\
\hline GFC Period & 0.994 & 0.996 & 0.985 & 0.980 & 0.996 & 0.991 & 0.990 & 0.993 & 0.935 & 0.933 & 0.978 \\
\hline EDC Period & 0.875 & 0.886 & 0.774 & 0.714 & 0.828 & 0.656 & 0.656 & 0.820 & 0.186 & 0.531 & 0.287 \\
\hline
\end{tabular}

Panel D: Asymmetric Dynamic Conditional Correlations (ADCC)

\begin{tabular}{|c|c|c|c|c|c|c|c|c|c|c|c|}
\hline & \multicolumn{9}{|c|}{ Group A } & \multicolumn{5}{c|}{ Group B } \\
\hline & BEL & FRC & GER & ITA & NET & SPN & AUS & FIN & GRC & IRE & POR \\
\hline Normal Period & 1.000 & 1.000 & 1.000 & 0.999 & 0.999 & 1.000 & 0.999 & 0.999 & 0.998 & 0.975 & 0.999 \\
\hline GFC Period & 0.997 & 0.998 & 0.994 & 0.991 & 0.998 & 0.997 & 0.995 & 0.997 & 0.973 & 0.974 & 0.991 \\
\hline EDC Period & 0.937 & 0.943 & 0.879 & 0.844 & 0.910 & 0.809 & 0.938 & 0.906 & 0.365 & 0.719 & 0.523 \\
\hline
\end{tabular}


Panel E1: Dynamic Co-integration Trace Statistic

\begin{tabular}{|c|c|c|c|c|c|c|c|c|c|c|c|}
\hline & \multicolumn{9}{|c|}{ Group A } & \multicolumn{5}{c|}{ Group B } \\
\hline & BEL & FRC & GER & ITA & NET & SPN & AUS & FIN & GRC & IRE & POR \\
\hline Normal Period & 0.686 & 0.865 & 0.721 & 0.916 & 0.498 & 0.720 & 0.452 & 0.626 & 0.689 & 1.241 & 0.382 \\
\hline GFC Period & 0.549 & 0.532 & 0.604 & 0.572 & 1.125 & 0.771 & 0.501 & 0.907 & 0.617 & 0.453 & 0.685 \\
\hline EDC Period & 0.703 & 0.520 & 0.553 & 0.516 & 0.564 & 0.712 & 0.464 & 0.563 & 0.489 & 0.676 & 0.610 \\
\hline
\end{tabular}

Panel E2: Dynamic Co-integration ECT Coefficient

\begin{tabular}{|c|c|c|c|c|c|c|c|c|c|c|c|}
\hline & \multicolumn{9}{|c|}{ Group A } & \multicolumn{5}{c|}{ Group B } \\
\hline & BEL & FRC & GER & ITA & NET & SPN & AUS & FIN & GRC & IRE & POR \\
\hline Normal Period & 0.285 & 0.403 & 0.193 & 0.205 & 0.268 & 0.306 & 0.285 & 0.210 & 0.132 & 0.106 & 0.113 \\
\hline GFC Period & 0.187 & 0.199 & 0.089 & 0.106 & 0.290 & 0.248 & 0.122 & 0.161 & 0.077 & 0.031 & 0.083 \\
\hline EDC Period & 0.023 & 0.035 & 0.010 & 0.021 & 0.034 & 0.051 & 0.014 & 0.016 & 0.007 & 0.006 & 0.017 \\
\hline
\end{tabular}

Panel F: Market Synchronisation (Bull Phase)

\begin{tabular}{|c|c|c|c|c|c|c|c|c|c|c|c|}
\hline & \multicolumn{6}{|c|}{ Group A } & \multicolumn{5}{c|}{ Group B } \\
\hline & BEL & FRC & GER & ITA & NET & SPN & AUS & FIN & GRC & IRE & POR \\
\hline Normal Period & 0.972 & 0.986 & 0.859 & 0.987 & 0.886 & 0.996 & 0.997 & 0.885 & 0.917 & 0.936 & 0.952 \\
\hline GFC Period & 0.997 & 0.997 & 0.912 & 0.994 & 0.965 & 0.998 & 0.989 & 0.959 & 0.948 & 0.952 & 0.986 \\
\hline EDC Period & 0.728 & 0.900 & 0.767 & 0.658 & 0.786 & 0.797 & 0.889 & 0.777 & 0.371 & 0.651 & 0.247 \\
\hline
\end{tabular}

Panel G1: Common Factors Approach

(Adjusted $R$-squares from the rolling regression on a priori Regional Common Factors)

\begin{tabular}{|c|c|c|c|c|c|c|c|c|c|c|c|}
\hline & \multicolumn{9}{|c|}{ Group A } & \multicolumn{5}{c|}{ Group B } \\
\hline & BEL & FRC & GER & ITA & NET & SPN & AUS & FIN & GRC & IRE & POR \\
\hline Normal Period & 0.998 & 0.998 & 0.998 & 0.996 & 0.996 & 0.997 & 0.996 & 0.997 & 0.996 & 0.960 & 0.997 \\
\hline GFC Period & 0.995 & 0.997 & 0.990 & 0.986 & 0.996 & 0.993 & 0.991 & 0.994 & 0.954 & 0.951 & 0.984 \\
\hline EDC Period & 0.891 & 0.912 & 0.854 & 0.789 & 0.880 & 0.731 & 0.902 & 0.877 & 0.306 & 0.559 & 0.346 \\
\hline
\end{tabular}

Panel G2: Common Factors Approach

(Adjusted $R$-squares from the rolling regression on Statistical Factors Obtained from PCA)

\begin{tabular}{|c|c|c|c|c|c|c|c|c|c|c|c|}
\hline & \multicolumn{9}{|c|}{ Group A } & \multicolumn{5}{c|}{ Group B } \\
\hline & BEL & FRC & GER & ITA & NET & SPN & AUS & FIN & GRC & IRE & POR \\
\hline Normal Period & 0.999 & 0.999 & 1.000 & 0.997 & 0.999 & 0.999 & 0.998 & 0.999 & 0.998 & 0.994 & 0.999 \\
\hline GFC Period & 0.996 & 0.998 & 0.996 & 0.988 & 0.998 & 0.994 & 0.993 & 0.997 & 0.987 & 0.974 & 0.991 \\
\hline EDC Period & 0.879 & 0.951 & 0.910 & 0.718 & 0.942 & 0.719 & 0.952 & 0.940 & 0.737 & 0.748 & 0.674 \\
\hline
\end{tabular}

(Note) Abbreviations are as follows $\mathrm{BEL}=$ Belgium; FRC=France; $\mathrm{GER}=$ Germany; ITA=Italy; NET=Netherlands; $\mathrm{SPN}=$ Spain; AUS=Austria; FIN=Finland; GRC $=$ Greece; IRE $=$ Ireland; $\mathrm{POR}=$ Portugal; $\mathrm{GFC}=$ Global Financial Crisis; EDC=European Debt Crisis. 
The table reports the results of the seven indicators of integration used in this study to measure bond market integration in EMU. (i) Beta Convergence measures the speed of convergence, (ii) Sigma Convergence is used to gauge the dispersion in returns relative to a benchmark, (iii) Variance Ratio examines the significance of a common regional factor in explaining the national returns variation, (iv) Dynamic Correlations are estimated using ADCC-EGARCH model to measure time varying integration based on correlations of the conditional volatility of returns, (v) Dynamic Co-integration analysis involves long-run common stochastic trend analysis which is dynamic in nature. This is augmented by estimating the time-varying parameter of ECT to measure the speed of adjustment to equilibrium. (vi) Market Synchronisation Correlation is quantified as the unconditional correlation between the logits of the regime (bull/bear) probabilities of two markets; i.e., country $i$ and EMU index. (vii) Common Factors Approach provides an alternative to the price convergence measures as it defines integration as the state of markets being significantly affected by the common global factors.

\section{A. Beta convergence}

Figure 1 presents the dynamic beta coefficients for the sample economies. For all the sample economies, the beta coefficient is negative, thus implying the presence of convergence throughout the sample period. 
Figure 1. Beta convergence

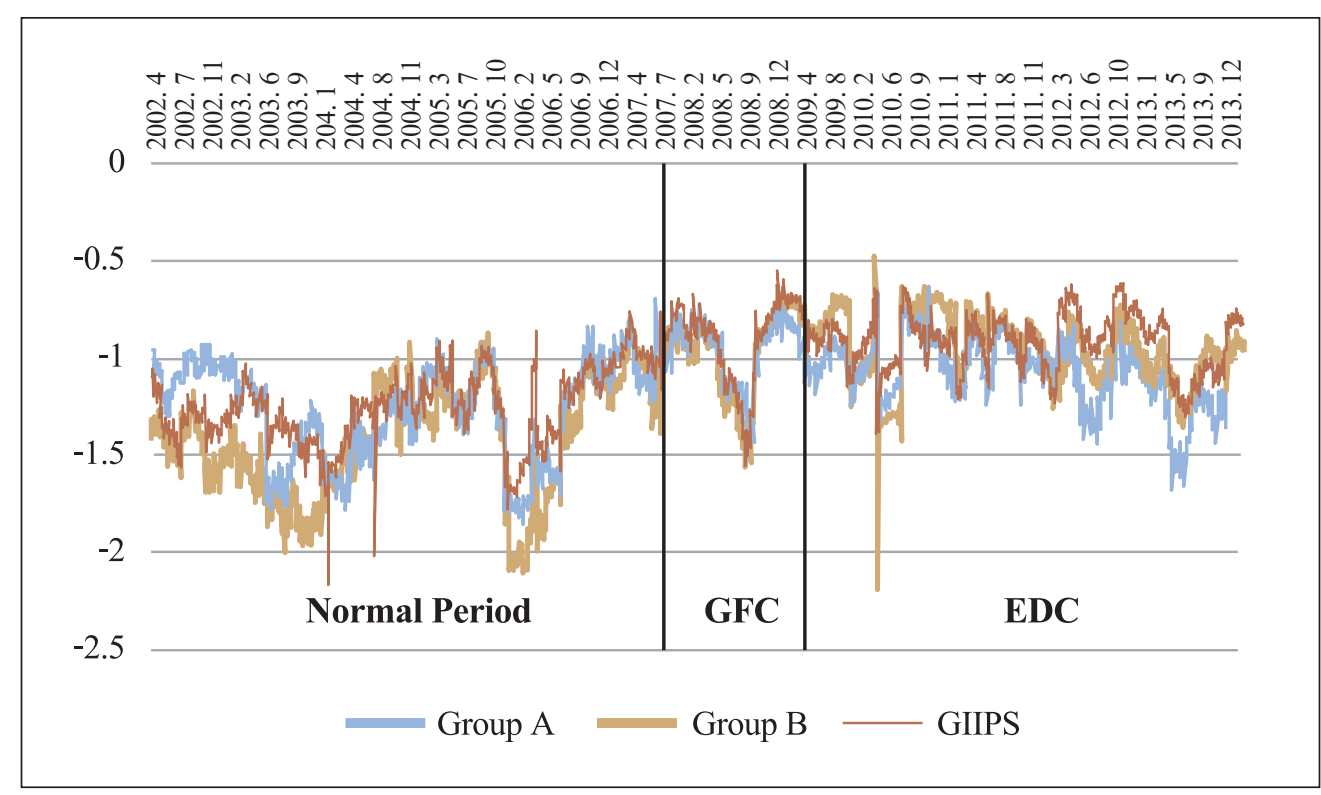

(Notes) (i) Abbreviations are as follows GFC=Global Financial Crisis; EDC=European Debt Crisis; GIIPS= Greece, Ireland, Italy, Portugal, and Spain.

(ii) Group A comprised of Germany, France, Italy spain, Netherlands, and Belgium, Group B comprised of Austria, Greece, Finland, Portugal, and Ireland.

The figure displays the usage of the rolling Beta values that measure levels of Beta Convergence for Normal Period, GFC, and EDC for Group A, Group B, and the GIIPS group.

Panel A of Table 2 depicts the average beta coefficients for the sample countries for each sub-period. The results show that except Germany and Italy, the beta coefficient values of all other Group A countries as well as Group B countries remain smaller than -1 during the Normal period. As Figure 2 suggests, during the normal period, the values lie between -1 and -2 , thus implying that the sample countries seem to follow an oscillating convergence with EMU. However, after the onset of crisis, the values generally range between -1 and 0 , thus indicating the process of monotonous convergence.

Generally, as we move from normal to crisis period, the speed of convergence, measured by the absolute value of beta coefficient, declines during the GFC period. This implies that the convergence process slowed down during the crisis. However, the speed was observed to improve towards the end of the sample period, implying progress towards recovery. 


\section{B. Sigma convergence}

Figure 2 presents the sigma convergence for the Group A and B economies over the sample period. The average values of sigma convergence are reported in Panel B of Table 2. The

Figure 2. Sigma convergence

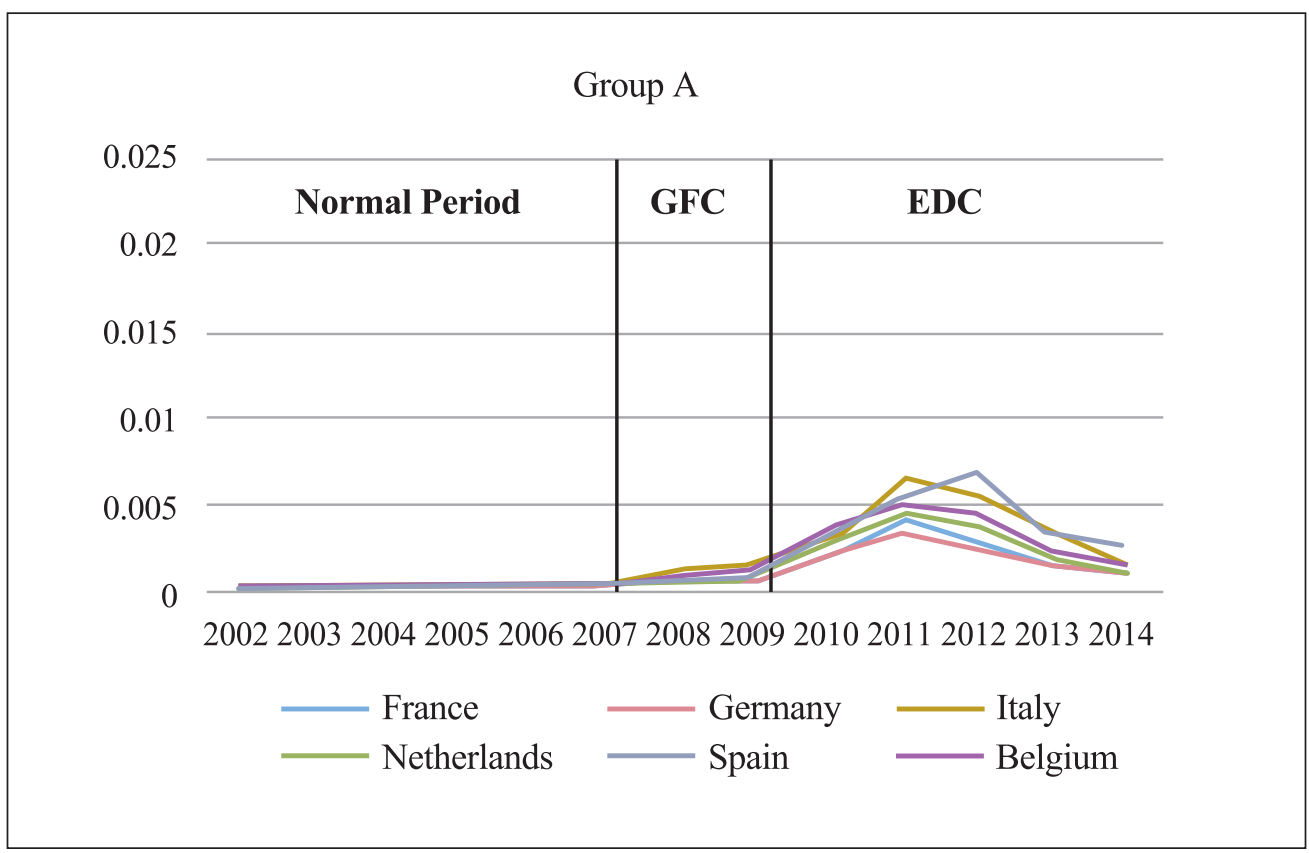




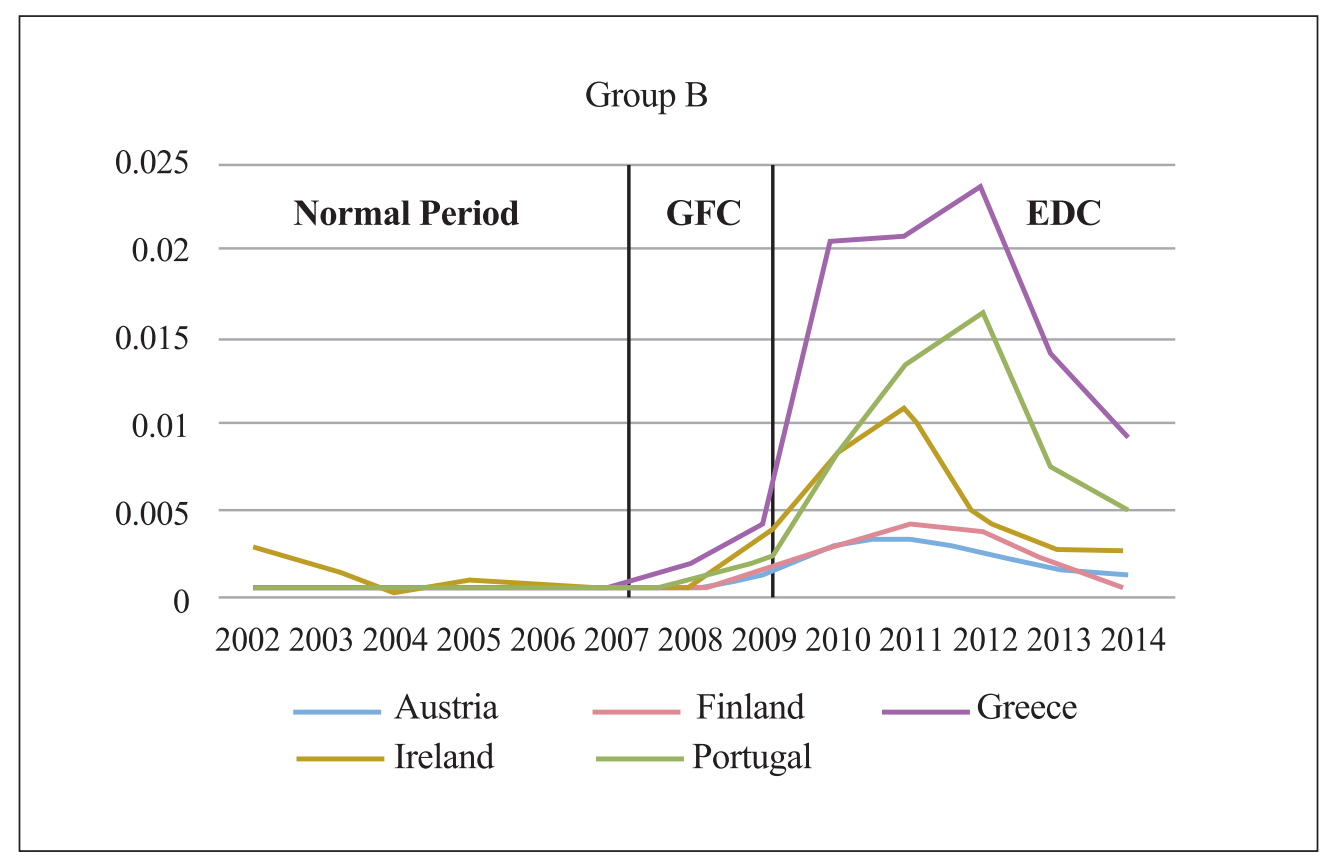

(Note) Abbreviations are as follows GFC $=$ Global Financial Crisis; EDC=European Debt Crisis.

The figure displays the values of cross-sectional dispersion that represent levels of dynamic Sigma Convergence for Normal Period, GFC, and EDC displayed separately for Group A and Group B countries.

The results show that during the Normal Period until 2007, the dispersion of country $i$ 's bond returns from EMU's bond returns was negligible as the sigma values remained close to zero. However, following the onset of GFC during the late 2007, we observe an increasing trend in dispersion. Further, the integration process experienced a setback at the end of 2009 as the EDC set in. During this period, sigma convergence registered a steep increase in values across all sample countries. It is noteworthy that the troubled GIIPS economies showed more dispersion than other members. Amongst these, the convergence of Greece and Portugal were the worst affected by the debt crisis. However, we observe a downward trend in the sigma values from 2013 onwards. This may be indicative of the resurgence of integration, as the economies have begun to recuperate.

Overall, it can be concluded that there are no stark differences between Group A and Group B in terms of financial integration. Both the groups experienced a strong integration during Normal period followed by deterioration in convergence during the crisis periods. However, the GIIPS economies experienced steep deterioration in their 
integration levels during the EDC.

\section{Variance ratio}

Figure 3 plots the average variance ratio for Group A and B over time, while Panel C of Table 2 reports the average values for each country across the sub-periods.

Figure 3. Variance ratio

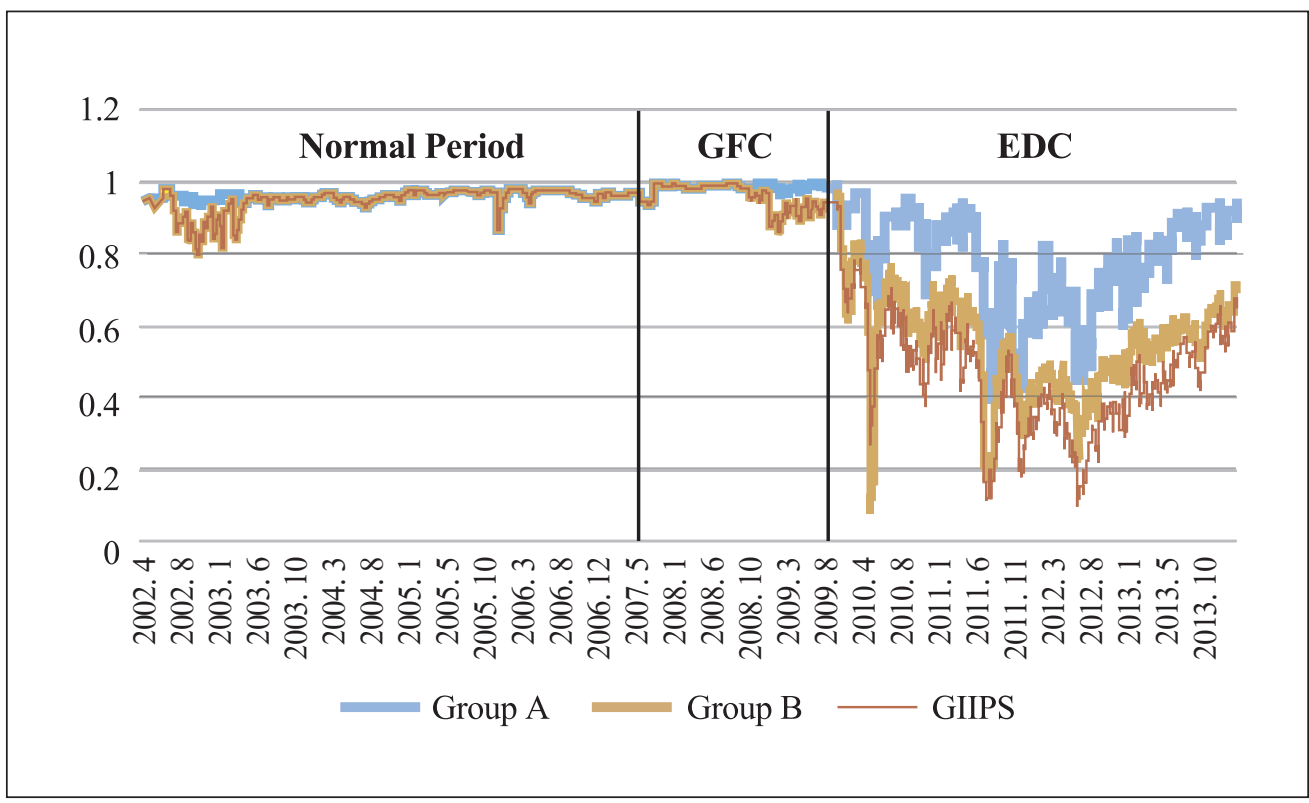

(Notes) (i) Abbreviations are as follows GFC=Global Financial Crisis; EDC=European Debt Crisis; GIIPS= Greece, Ireland, Italy, Portugal, and Spain.

(ii) Group A comprised of Germany, France, Italy spain, Netherlands, and Belgium, Group B comprised of Austria, Greece, Finland, Portugal, and Ireland.

The figure displays the values of the variance ratio that represent levels of Variance Ratio for Normal Period, GFC, and EDC for Group A, Group B, and GIIPS economies.

We observe that during the Normal Period, bond indices of all the sample economies exhibit a very strong integration with the EMU's bond index. Ireland did not show high integration with the EMU during the initial years of currency union; however, it exhibited improved levels of integration from the first quarter of 2003. 
The beginning of the GFC marked a further strengthening of the integration as shown by a slight increase in variance ratio. This increase should be interpreted with caution as it may signal contagion. However, as the GFC progressed, the GIIPS economies display a declining trend in variance ratio. The onset of EDC marks a significant setback in the integration process for all the sample economies as displayed by the steep decline in the variance ratio for these countries. The integration process of GIIPS economies was most negatively affected, with Greece and Portugal showing strong signs of disintegration. It is noteworthy that while Germany showed the highest level of integration amongst all countries during the normal period, France remained the most resilient and highly integrated bond market during the crisis periods.

\section{Asymmetric dynamic conditional correlation}

The ADCC-GARCH model provides the estimates of dynamic correlation as a measure of integration between country $i$ and EMU. The EGARCH $(1,1)$ estimation ${ }^{11}$ shows that long-run volatility persistence as measured by $\psi_{j}$ in Equation (8) is statistically significant and very high, ranging over 0.93 throughout the sample period for all the markets. The asymmetric effects of news on volatility were found to be significant for most of the countries during the Normal period and for all sample countries during the crisis periods, thus justifying the use of the $\operatorname{EGARCH}(1,1)$ model to generate conditional variances of the returns. The estimation of ADCC equation ${ }^{12}$ reveals highly significant values of $\theta_{1}$ and $\theta_{2}$ for Equation (9) throughout the sample period. This indicates the presence of significant time varying co-movements of the markets with the EMU during normal as well as crisis periods. The conditional correlation exhibits high persistence as reflected by the near unity values of $\left(\theta_{1}+\theta_{2}\right)$ across all sample countries throughout our study period. The asymmetrical influence of joint bad news (Cappiello et al. 2006) on correlation coefficient between country $i$ and EMU, as measured by $g$ in Equation (9), is reported to be significant for most of the markets during the normal period. However, during the GFC, $g$ is statistically insignificant for all sample economies except Greece, thus implying that after the markets absorbed the news of global downturns, it stopped being the driving force behind markets' co-movements in the

\footnotetext{
${ }^{11}$ The results are shown in Appendix 3.

${ }^{12}$ Please refer to Appendix 3.
} 
EMU. Further, during EDC, $g$ becomes significant again, suggesting that the common bad news of fractures in the EMU emerged as the major force behind the markets' comovements during this period.

Figure 4. Asymmetric dynamic conditional correlation

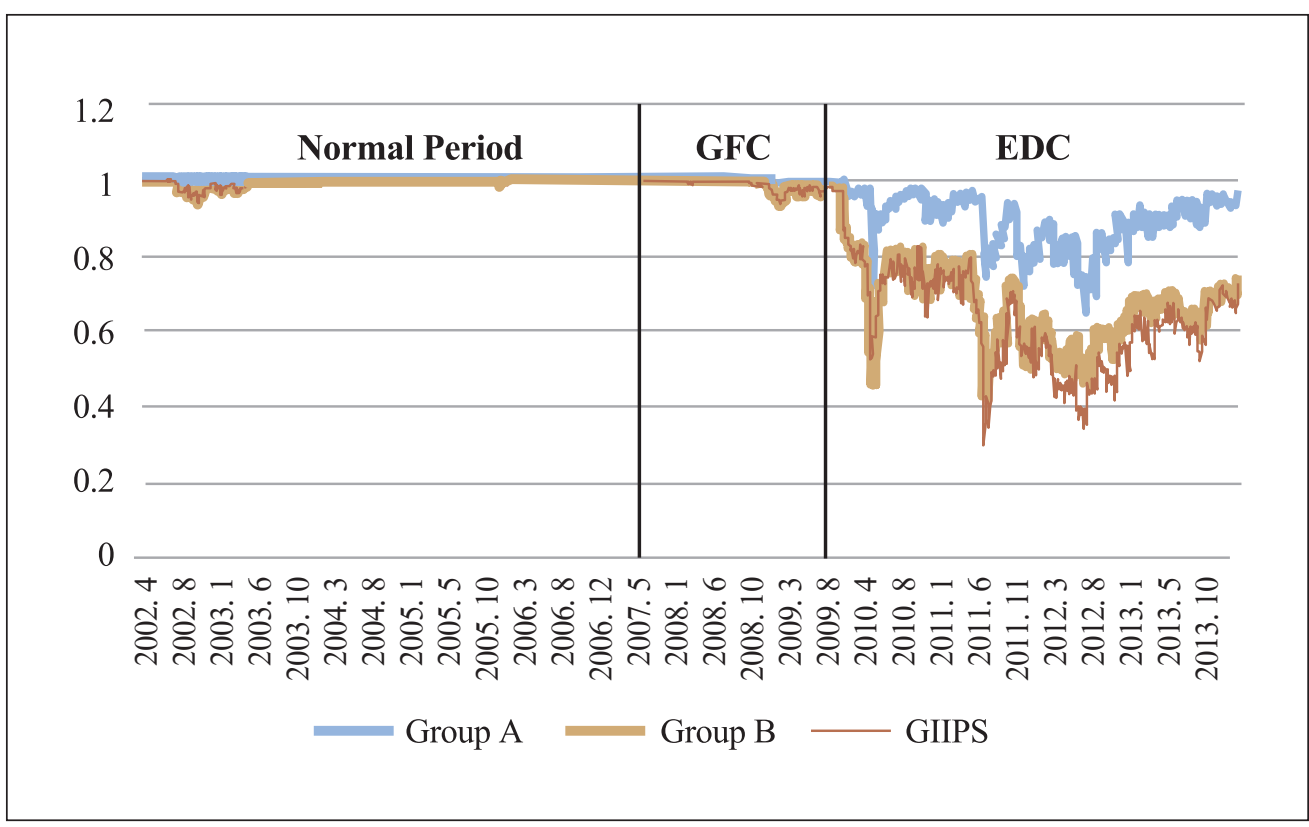

(Notes) (i) Abbreviations are as follows $\mathrm{GFC}=$ Global Financial Crisis; EDC=European Debt Crisis; GIIPS= Greece, Ireland, Italy, Portugal, and Spain.

(ii) Group A comprised of Germany, France, Italy spain, Netherlands, and Belgium, Group B comprised of Austria, Greece, Finland, Portugal, and Ireland.

The figure shows the average dynamic correlation of the EMU bond returns with the bond returns of Group A, Group B, and GIIPS economies respectively.

Figure 4 provides an overview of the dynamic coefficient of correlation for the sample countries over time. Panel D of Table 2 reports the average values of correlation for each economy across the three sub-periods. ADCC confirms the results of Variance Ratio Analysis, with the only exception that the beginning of GFC marks no change in the level of integration. However, towards the end of GFC, the integration progress of GIIPS economies breaks down as depicted by the declining trend in the values of correlation coefficients. With the beginning of EDC, all economies experienced a severe setback in the integration process. The GIIPS economies continue to show further 
deterioration in integration as shown by low values of correlation during this period. Again, Greece and Portugal remain worst affected amongst the GIIPS countries. France and Belgium from Group A, and Austria and Finland from Group B were the most resilient economies as they continued to show very high correlation values during both the crisis periods.

Here, an important caveat is that increased correlations do not necessarily mean integrated bond markets, as they may be on account of strong policy externalities in the EMU, wherein the macroeconomic and financial situation in one of the member countries have substantial impact on others. This indicator stands good only to the extent that the stochastic process of common shocks is constant over time, which is unlikely considering the dynamic process of real economic integration in the region.

\section{E. Dynamic co-integration}

The long-run convergence between country $i$ and EMU is assessed by rolling trace statistics scaled by its critical value, where a value greater than one indicates the presence of long-run convergence. 


\section{Figure 5. Rolling trace statistics}

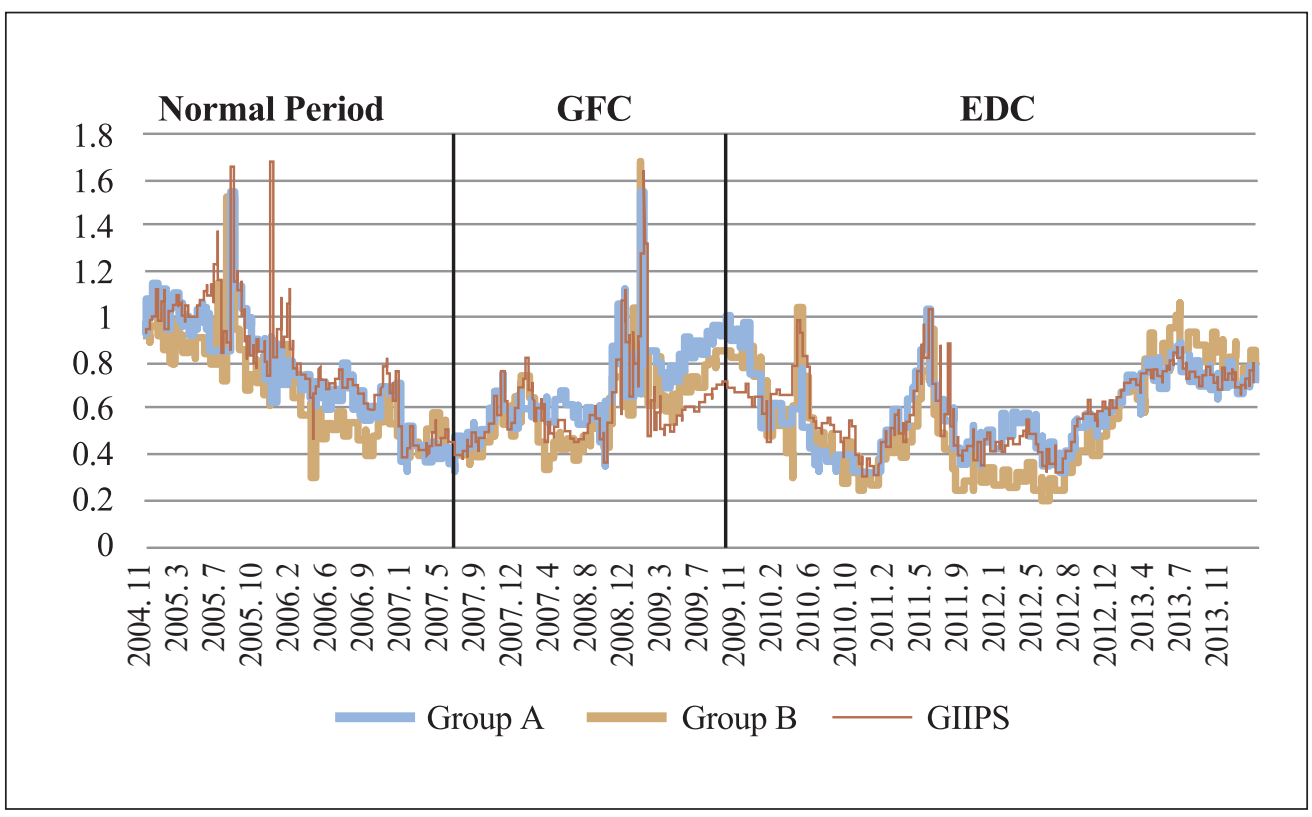

(Notes) (i) Abbreviations are as follows GFC=Global Financial Crisis; EDC=European Debt Crisis; GIIPS= Greece, Ireland, Italy, Portugal, and Spain.

(ii) Group A comprised of Germany, France, Italy spain, Netherlands, and Belgium, Group B comprised of Austria, Greece, Finland, Portugal, and Ireland.

The figure displays the 750 trading days, approximately 3 years, rolling unweighted average trace statistics scaled by its critical value for each group and GIIPS economies across the three sub-periods, viz. Normal Period, GFC, and EDC.

Figure 5 displays the rolling trace statistic for the members of Group A and Group $B$, respectively across the three sub-periods. The trace statistics do not reveal any clear pattern throughout the sample period. The Group A economies, except the Netherlands, exhibit co-integration with the EMU during the initial stage of the monetary union up to 2006, after which, co-integration remained absent for the rest of the normal period. On the other hand, the Group B economies, except Ireland, did not show any signs of co-integration during the Normal period. Ireland exhibits similar trends as the Group A economies as it showed co-integration with the EMU only up to 2006 during the normal period. The sub-period beginning towards the fourth quarter of 2008 up to the first quarter of 2009 is interesting as it witnessed a high convergence, especially in the case of Spain, Portugal, Ireland, Greece, France, Finland, and the Netherlands. This period 
coincides with the peak of GFC. This convergence may be on account of contagion, particularly because Spain and Portugal are considered the epicentres of EDC and along with Greece and Ireland, they belong to the troubled GIIPS group while France, Finland, and the Netherlands are amongst the economies with the highest exposure to GIIPS (Cliffe et al. 2012). Both Spain and Portugal again showed a couple of spikes during the middle of 2009 and of 2010. It is noteworthy that Spain created a bailout fund in mid-2009 and urged the weaker savings banks to merge, and both Spain and Portugal announced new austerity measures during May 2010. ${ }^{13}$ Apart from this, there are no upward or downward trend observed as the regime shifted from normal to crisis period. Interestingly, the trace statistic started climbing for almost all the economies from June 2013 onwards, implying improved co-integration. This may mark the end of the euro zone crisis and a possible recovery beyond this.

Figure 6. Dynamic co-integration: coefficient of error correction term

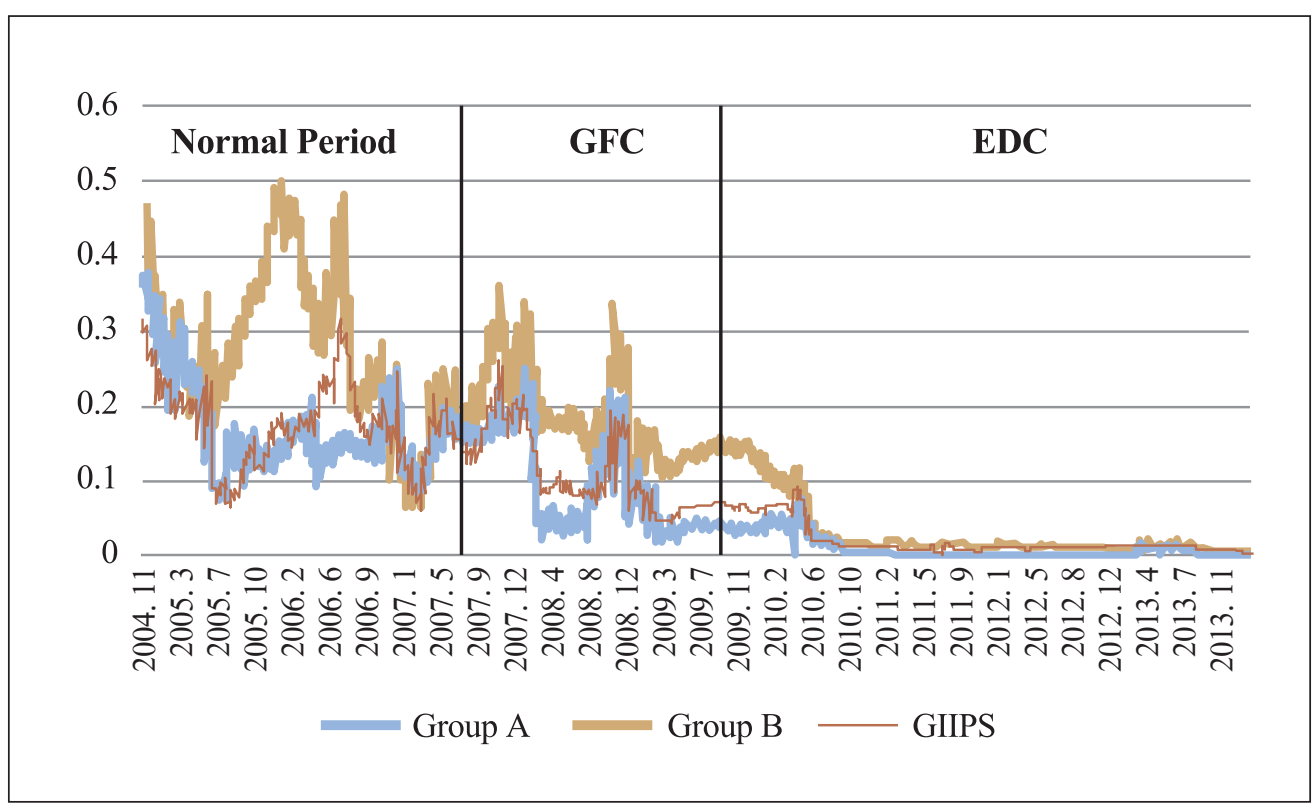

(Notes) (i) Abbreviations are as follows GFC=Global Financial Crisis; EDC=European Debt Crisis; GIIPS= Greece, Ireland, Italy, Portugal, and Spain.

(ii) Group A comprised of Germany, France, Italy spain, Netherlands, and Belgium,

Group B comprised of Austria, Greece, Finland, Portugal, and Ireland.

${ }^{13}$ Retrieved on July 31, 2014, from http://www.telegraph.co.uk/finance/financialcrisis/8682034/Eurozone-debt-crisis-timeline.html. 
The figure displays the unweighted average of the absolute values of 750 trading days, approximately 3 years, rolling coefficient of the ECT generated from the Dynamic Co-integration analysis, for three sub-periods viz. the Normal Period, the GFC, and the EDC.

Another indicator of integration that stems from co-integration analysis is the speed of adjustment of the return series of country $i$ to correct deviation from long-run equilibrium with the EMU. The absolute value of the coefficient $(\alpha)$ of ECT measures the speed of the adjustment. A higher value of $\alpha$ implies greater response of the return series to deviation from long-run equilibrium, implying greater integration, thus moving towards a progressively higher degree of convergence. Figure 6 displays the rolling $\alpha$ coefficient for the sample countries in Groups A and B across the three sub-periods. We observe that overall the average alpha for Group A is higher than that for Group B, indicating a higher convergence level for Group A. In Group A, France showed the highest speed of adjustment during the Normal period. During the period between June 2005 and November 2006, Germany displayed a negative speed of adjustment implying that German bond returns were overpriced during this period compared to the EMU bond returns. In Group B, Austria and Finland were observed to be strongly converging, while the GIIPS members, i.e., Greece, Ireland, and Portugal, experienced severe setbacks during the crisis period. For both Groups A and B, the highest speed of adjustments is observed during the Normal period, after which there is a decline during the crisis periods. It is noteworthy that with the onset of EDC, the speed of adjustment of all sample economies dipped to zero, suggesting an absence of the correction of deviations from long-run equilibrium with the EMU. This moves towards the disintegration process during this period.

\section{F. Market synchronisation}

The MRS-AR's endogenous regime selection method divided the sample period into two regimes: bull phase and bear phase. We first checked the condition of non-linearity using the BDS test. The test results report that the null of IID is strongly rejected. ${ }^{14}$ As linear structures have been removed using the AR process, the rejection of null implies the presence of non-linear dependencies in the returns series (Panagiotidis 2002).

\footnotetext{
${ }^{14}$ To conserve space the results are not reported but are shown in Appendix 4.
} 
Panel F of Table 2 reports the values for the correlation of regime probabilities for the countries during the different sub-periods. These results reassert the observations made based on the results of the Variance Ratio and ADCC Analysis. All economies, except Austria, show a slight increase in correlation values from Normal to GFC period. During the latter period, the bond markets of these economies showed higher levels of synchronisation with that of EMU's as they experience the same phase of market cycle as EMU. Particularly, the Group A economies of Germany and the Netherland, and the Group B economy of Finland display a noteworthy increase in correlation during the GFC period, while for others, correlation remained nearly the same as during the Normal period. The advent of EDC period marked a steep deterioration in the levels of correlations, implying a pattern of disintegration. Amongst all the sample economies, the GIIPS economies were immensely impacted. Further, Portugal was the worst affected amongst these. This may be explained by the fact that Portugal is one of the countries, where the other being Spain, that are considered to be the origin of the crisis (Ahmad and Sehgal 2014).

\section{G. Common factors model}

The adjusted $R$-square $\left(\bar{R}^{2}\right)$ values obtained from the rolling estimation of Equation (15) gives the extent to which the variance in country $i$ 's return is explained by the regional common factors. Larger $\bar{R}^{2}$ implies a higher convergence with EMU. 
Figure 7. Rolling adjusted $\boldsymbol{R}$-square of the common factors approach

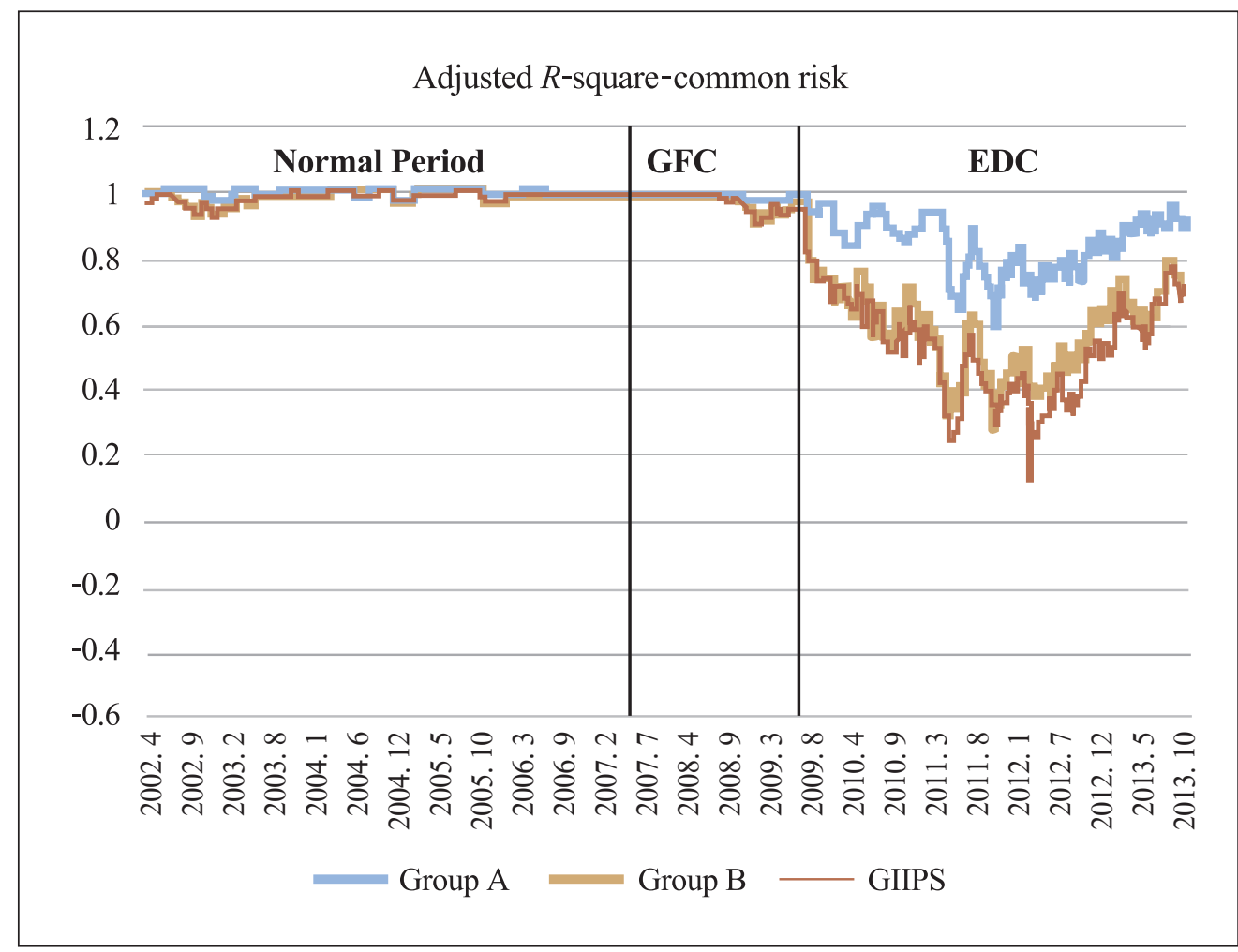

(Notes) (i) Abbreviations are as follows GFC=Global Financial Crisis; EDC=European Debt Crisis; GIIPS= Greece, Ireland, Italy, Portugal, and Spain.

(ii) Group A comprised of Germany, France, Italy spain, Netherlands, and Belgium, Group B comprised of Austria, Greece, Finland, Portugal, and Ireland. 


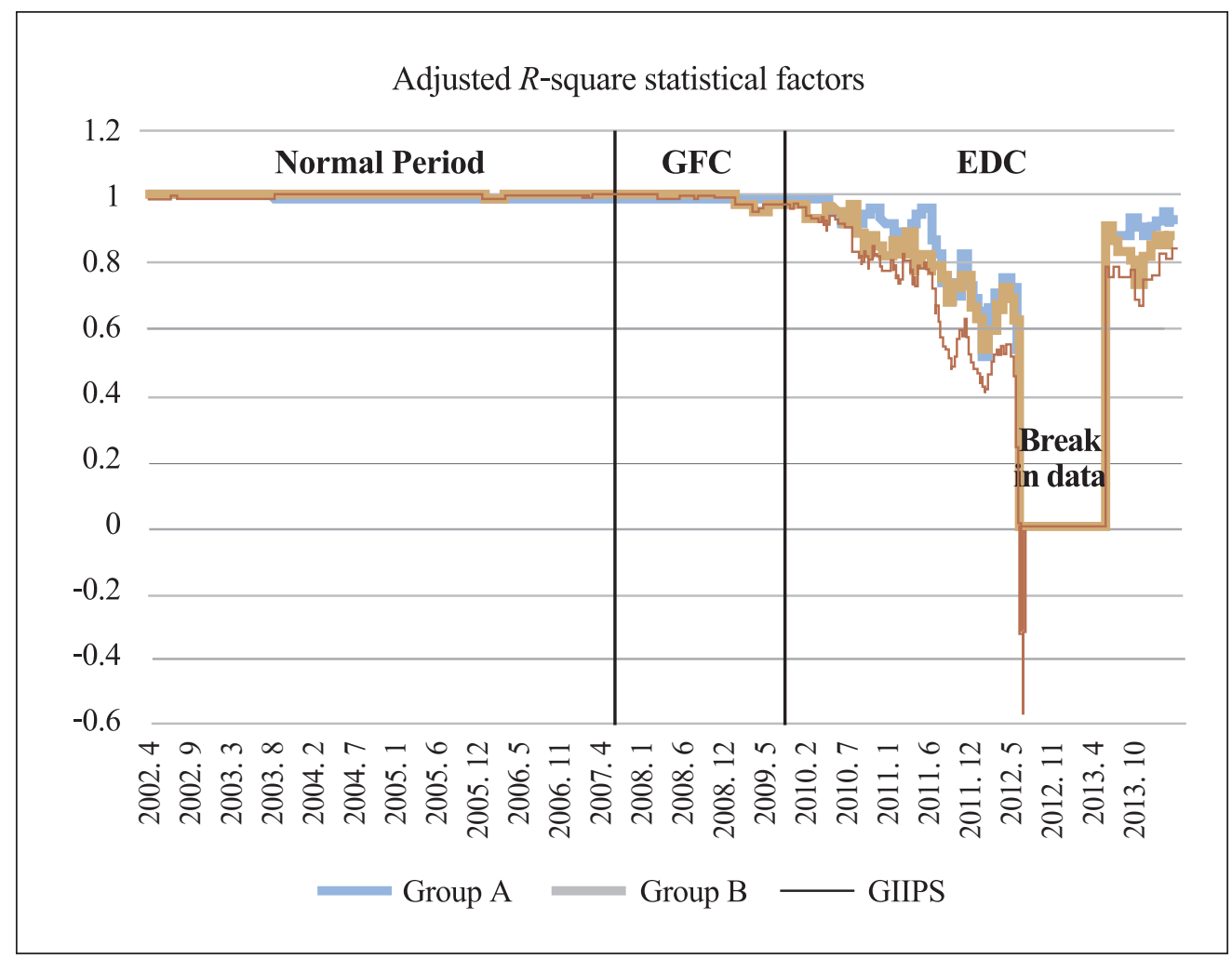

(Notes) (i) Abbreviations are as follows GFC=Global Financial Crisis; EDC=European Debt Crisis; GIIPS= Greece, Ireland, Italy, Portugal, and Spain.

(ii) Group A comprised of Germany, France, Italy spain, Netherlands, and Belgium, Group B comprised of Austria, Greece, Finland, Portugal, and Ireland.

(iii) Break in Data: Due to the unavailability of data for a particular period (July 2012 May 2013) in the return series of Greece, the Principal Component Analysis could not be executed for that period which caused a break in the estimation of regression on statistical factors.

The first panel of the figure displays the average rolling adjusted $R$-squares for Group A, Group B, and GIIPS economies, obtained from regressing country $i$ 's returns on the European Common Components. The second panel plots the average rolling adjusted $R$-squares for Group A, Group B, and GIIPS economies, obtained from the Principal Component Analysis.

Table 2 shows the average $\bar{R}^{2}$ values for each country for the three sub-periods. The results report very high $\bar{R}^{2}$ values (ranging over 0.95 ) during Normal period, thus indicating that the common factors explain almost all the variance of individual countries' bond returns during this period. With the onset of GFC period, a slight decline in $\bar{R}^{2}$ values is observed. Later on, towards the end of GFC period, the GIIPS economies, 
led by Greece, show a downward trend in the rolling $\bar{R}^{2}$ values. As the EDC period sets in, all economies register a decline in their respective $\bar{R}^{2}$ values. The GIIPS economies are worst affected with Greece and Portugal showing strong signs of disintegration as their average $\bar{R}^{2}$ values fall below $35 \%$. Hence, during the crisis period, the contribution of common factors decline, implying that idiosyncratic factors, such as respective sovereign risks, gained prominence, thus adversely affecting the process of regional integration. Amongst the sample economies, the non-GIIPS economies of France (Group A) and Austria (Group B) show resilience and strong integration with the EMU even during the crisis periods, where the average $R^{2}$ values being over 0.90 .

Furthermore, the Principal Component Analysis (PCA) identified two principal components (henceforth labelled as statistical factors) which had eigen values greater than one. ${ }^{15}$ In order to check the robustness of the results of the above regression analysis involving the a priori common factors, we regress country $i$ 's bond returns on the factors obtained from PCA. Panel G2 of Table 2 reports the average $\bar{R}^{2}$ values obtained from the rolling estimation of this regression. The results suggest that the empirical analysis is robust to using statistical factors in place of a priori identified common factors. The factor loadings corresponding to the first principal component are positive for the returns of all sample economies. Using auxiliary regression, ${ }^{16}$ we identified it as returns on the EMU bond index, which has been employed as one of the a priori common factors. However, the other statistical factor could not be identified with any of the $a$ priori common factors. It is interesting to note that the factor loadings corresponding to the second principal component are negative for Austria, Belgium, Finland, France, Germany, and the Netherlands, while they are positive for the economies of Greece, Portugal, Spain, Ireland, and Italy. As such, the two groups identified by this component coincided with the so-called non-GIIPS and GIIPS economies of the EMU. Hence, the second principal component represents a discriminatory factor that captures the heterogeneity between the GIIPS and non-GIIPS groups as its loadings on returns vary in signs (positive and negative) across countries, corresponding to the investors' perception of higher versus lower sovereign risk. Further, the results reveal the redundancy of the three other a priori factors that are commonly used in prior research. They do not seem to find a place in the factor component approach, implying that they do not contribute to the pricing of risk on bonds.

\footnotetext{
${ }^{15}$ The results are shown in Appendix 5.

${ }^{16}$ Please refer to Appendix 5.
} 


\section{EMU Bond and Stock Markets}

With the increase in globalisation, different segments of financial markets are linked more than ever due to the quick dissemination of information, common market players who have exposure in different segments simultaneously, as well as the increasingly diversified and global nature of portfolio and asset allocation. As such, it is important to understand the cross-asset market relationships between the two important segments of capital market, namely the equity and bond market from the perspective of financial integration. This issue warrants attention given the importance of correlations between different asset classes for portfolio construction as well as for the efficient management of financial systems and monetary policy formulation. This shall help us in assessing the market that takes the lead position and drives integration in other segments of financial markets. It has implication from the perspective of policy formation both in the time of normal period when pro-integration steps are required and during crisis when anticontagion and disintegration-containing steps are warranted.

For gauging the linkages between the equity returns and bond returns, we employ the bivariate co-integration (Johansen 1991) to test for the presence of long-run relationship along with Vector Error Correction Model (VECM) to gauge the short-term correction paths. This is augmented by the Granger Causality Test to check the direction of linkages between the two segments for each country of the sample set. 
Table 3. Information linkages between bond and stock markets

\begin{tabular}{|c|c|c|c|c|c|}
\hline & & \multicolumn{2}{|c|}{ Coefficient of ECT ${ }^{b}$} & \multicolumn{2}{|c|}{ Granger Causality } \\
\hline & $\mathrm{n}^{\mathrm{a}}$ & r_stock & r_bond & Stock $>$ Bond & Bond $>$ Stock \\
\hline Austria & 1 & $\begin{array}{c}-0.130 \\
{[-11.628]^{* *}}\end{array}$ & $\begin{array}{c}-0.775 \\
{[-36.687]^{* *}}\end{array}$ & $\begin{array}{c}0.000 \\
(0.997)\end{array}$ & $\begin{array}{c}17.139 \\
(0.000)^{*}\end{array}$ \\
\hline Belgium & 1 & $\begin{array}{c}-0.017 \\
{[-7.461] * *}\end{array}$ & $\begin{array}{c}-0.144 \\
{[-37.580] * *}\end{array}$ & $\begin{array}{c}0.007 \\
(0.934)\end{array}$ & $\begin{array}{c}4.675 \\
(0.031)^{*}\end{array}$ \\
\hline Finland & 1 & $\begin{array}{c}-0.006 \\
{[-1.956]^{* *}}\end{array}$ & $\begin{array}{c}0.205 \\
{[36.623]^{* *}}\end{array}$ & $\begin{array}{l}0.019 \\
(0.89)\end{array}$ & $\begin{array}{c}2.674 \\
(0.102)\end{array}$ \\
\hline France & 1 & $\begin{array}{c}-0.017 \\
{[-3.286] * *}\end{array}$ & $\begin{array}{c}0.382 \\
{[39.134]^{* *}}\end{array}$ & $\begin{array}{c}0.000 \\
(0.989)\end{array}$ & $\begin{array}{c}2.803 \\
(0.094)^{*}\end{array}$ \\
\hline Germany & 1 & $\begin{array}{c}-0.114 \\
{[-9.211] * *}\end{array}$ & $\begin{array}{c}0.735 \\
{[29.707]^{* *}}\end{array}$ & $\begin{array}{c}0.132 \\
(0.717)\end{array}$ & $\begin{array}{c}1.959 \\
(0.162)\end{array}$ \\
\hline Greece & 1 & $\begin{array}{c}0.000 \\
{[0.000]}\end{array}$ & $\begin{array}{c}0.309 \\
{[36.168]^{* *}}\end{array}$ & $\begin{array}{l}0.738 \\
(0.39)\end{array}$ & $\begin{array}{c}0.069 \\
(0.793)\end{array}$ \\
\hline Ireland & 1 & $\begin{array}{c}0.000 \\
{[0.060]}\end{array}$ & $\begin{array}{c}0.367 \\
{[29.972]^{* *}}\end{array}$ & $\begin{array}{c}0.728 \\
(0.394)\end{array}$ & $\begin{array}{c}1.144 \\
(0.285)\end{array}$ \\
\hline Italy & 1 & $\begin{array}{c}-0.125 \\
{[-15.267]^{* *}}\end{array}$ & $\begin{array}{c}-0.584 \\
{[-37.618]^{* *}}\end{array}$ & $\begin{array}{c}0.011 \\
(0.918)\end{array}$ & $\begin{array}{c}3.005 \\
(0.083)^{*}\end{array}$ \\
\hline Netherlands & 1 & $\begin{array}{c}-0.102 \\
{[-9.009] * *}\end{array}$ & $\begin{array}{c}0.745 \\
{[33.966]^{* *}}\end{array}$ & $\begin{array}{c}0.205 \\
(0.651)\end{array}$ & $\begin{array}{c}2.310 \\
(0.129)\end{array}$ \\
\hline Portugal & 1 & $\begin{array}{c}0.008 \\
{[7.513]^{* *}}\end{array}$ & $\begin{array}{c}0.048 \\
{[38.119]^{* *}}\end{array}$ & $\begin{array}{c}0.198 \\
(0.657)\end{array}$ & $\begin{array}{c}0.712 \\
(0.399)\end{array}$ \\
\hline Spain & 1 & $\begin{array}{c}-0.020 \\
{[-9.135]^{* *}}\end{array}$ & $\begin{array}{c}-0.154 \\
{[-39.877]^{* *}}\end{array}$ & $\begin{array}{c}0.372 \\
(0.542)\end{array}$ & $\begin{array}{c}0.270 \\
(0.604)\end{array}$ \\
\hline
\end{tabular}

(Notes) (i) ${ }^{\mathrm{a}} \mathrm{n}$ denotes the number of co-integration vectors between the returns of stock market and bond market for each sample country. ${ }^{\mathrm{b}}$ ECT denotes the Error Correction Term from the VECM analysis.

(ii) Values in [ ] show the $t$-statistics. ** indicates at 5\% level of significance and better.

Values in ( ) show the $p$-values. * indicates at $10 \%$ level of significance and better.

The table reports the results of the Cointegration Analysis that tests for the presence of long-run relationship and ECT from VECM to gauge the short-term correction paths. In addition, the results of the Granger Causality Test reveal the direction of linkages between the two segments for each sample economy. 
The results reveal the presence of two co-integrating vectors between the returns of bond market and stock market for each of the sample economies. This indicates a strong, long-run equilibrium relationship between the two segments of capital markets in all the economies. Further, we analyse the coefficient of Error Correction Term (ECT), $\alpha$, in the VECM framework. The absolute value of $\alpha$ measures the adjustment of a series to correct deviation from long-run equilibrium. Under the co-integration analysis of a pair of time series, the series with a smaller value of absolute $\alpha$ makes a smaller adjustment, implying that it deviates lesser from the long run equilibrium. Thus, such series are considered to be leading the relationship. We observe that the absolute values of $\alpha$ are smaller for the bond return series for all the sample countries without any exception. This strongly suggests that the bond market takes the lead in the information transmission process. The Granger Causality test produces a mixed picture, wherein no significant causal relationship is observed for most of the sample set, while for one-fourth of the set, significant causality exists from bond to stock market. Our results are in line with those of Berben and Jansen (2005) who studied time-varying financial integration in nine European countries and the US in the period 1980 2003. They concluded that stock market integration is a more gradual process than bond market integration. Similarly, in their study on the impact of the introduction of the euro on the integration of European financial markets, Cappiello et al. (2006) concluded that while the integration as measured by correlations in bond markets reaches almost one for all euro area countries, co-movements in equity markets are much lower.

These results explain the higher values of integration indicators for bond markets than those of stock markets in our previous work (Sehgal et al. 2014). In contrast to stock market indices, the characteristics of the underlying financial instruments, like maturity, coupon payments, the identity of the issuer, in case of bonds are similar across countries and remain relatively stable over time. From the perspective of policy-makers, these results imply the evolution of integration progresses from bond markets to stock markets. However, in the period of crisis, bond market disintegration and possible contagion shall proceed with a similar behaviour in stock markets. Hence, a more appropriate policy framework shall be to initiate the intervention strategies in crisis management in the bond market prior to the stock market. 


\section{Conclusion}

In this paper, we examined multiple dimensions of time-varying sovereign bond market integration in the EMU during normal and crisis periods, for 11 EMU member countries with active bond markets.

The main empirical findings are as follows:

1. The results for all the indicators show that Group A consisted with large-sized economies and Group B consisted with medium sized economies do not exhibit heterogeneity in their progress of integration over time, unlike in the case of EMU stock markets as shown in our previous study (Sehgal et al. 2014). The only clear distinction in the progress of integration was observed between the two categories, which are GIIPS and non-GIIPS economies during the crisis period. Thus, the bond market integration does not seem to be affected by the size of the economy.

2. The crisis is observed to have substantial impact on the integration process in the monetary union as shown by weaker results of indicators for the sample economies during EDC. In particular, the GIIPS economies exhibit substantially low integration levels during this period, which can be attributed to investors' perception of higher sovereign risk regarding these economies during EDC, leading to a steep rise in their yields compared to the average EMU yield. Amongst the GIIPS, Greece and Portugal were worst affected.

3. However, Battistini et al. (2013) note that setback in integration measures due to variation in sovereign risk across countries should not be concluded as segmentation as only that component of yield differentials which is not a reward for the issuer credit risk may reflect segmentation. Our results show that after the second half of 2012, there were signs of recovery of bond market integration as shown by the indicators. This improvement may be attributed to the decision by European leaders regarding the banking union and introduction of Outright Monetary Transactions (OMTs) announcement by the European Central Bank (ECB), which allows the Eurosytem to buy euro area government bonds on a potentially unlimited scale and thus provide benign market conditions.

4. It is noteworthy that while France emerged as the most steadily integrated bond market of the currency union, Germany, which is considered as the mirror image 
of the EMU bond market, exhibited notable setback during the EDC. This may be because of the heavy exposure of German sovereign debt in the GIIPS markets. From the policy perspective, Germany and perhaps other larger European markets must hold a more diversified debt market portfolio in the future.

5. The empirical results of this study also allow us to conclude that the bond market integration is stronger than the stock market integration in the Eurozone area in the normal phase, and that the bond markets suffered from greater disintegration in the crisis phase than the stock markets. ${ }^{17}$ Thus, bond markets exhibit greater sensitivity to economic cycles than stock markets.

6. Finally, our analysis of the linkages between bond and stock markets suggests that in the short run, bond markets merit a higher ranking on the integration and development policy preferences of the EMU as they were observed to lead stock markets in the information transmission process.

We present the following policy implications concerning the EMU bond market integration:

1. From the policy-making perspective, any integration strategy should first focus on bond markets followed by the stock markets.

2. Also, the crisis-intervention strategies should first be initiated in bond markets, with particular focus on the GIIPS economies.

3. Investors' perception of sovereign risk of a country emerged as an important "discriminating factor" in the PCA Analysis. Thus, countries with higher perceived sovereign risk (thus, lower credit rating) such as GIPSI economies are observed to have less integrated bond market. This highlights the importance of strong fundamentals for higher degree of convergence.

4. A stable bond market integration process pre-requires the existence of deep, developed, and sound bond markets across member nations. The banking system, which operates as a parallel source of long-term debt in many economies, poses a challenge for the development of long-term debt markets.

5. Furthermore, with an exception of few developed economies, the debt market system is also plagued by the absence of deep derivative markets that provide a potent platform for risk hedging.

\footnotetext{
${ }^{17}$ For stock market integration, see Sehgal et al. 2014.
} 
6. In addition, differential in administrative costs across countries, such as varied stamp duties, different taxation structures, and other trading costs also disrupts any integration.

7. Policy-makers should also address the issue of poor governance systems and inadequate disclosure policies that facilitate illegal practices such as pilferage of public funds, thus weakening the fundamentals (Katsimi and Moutos 2010, Featherstone 2011). These factors lead to a variation in depth, strength, and development of debt markets across countries, resulting in a less than expected level of integration.

The study has important implications for the policy-makers in EMU and worldwide in light of enhanced interdependence amongst economies, increasingly global nature of financial risks, as well as a growing number of regional co-operation initiatives worldwide. Further research on Eurozone integration should essentially focus on assessing multiple dimensions of integration from the perspective of the banking sector, money market, the alternative investment markets, and the corresponding derivative markets.

Received 13 February 2015, Revised 25 September 2015, Accepted 20 October 2015

\section{References}

Abad, P., Chuliá, H., and Gómez-Puig, M. "EMU and European government bond market integration.” Journal of Banking and Finance 34 (2010): 2851-2860.

Abad, P., Chuliá, H., and Gómez-Puig, M. "Time Varying Integration in European Government Bond Markets.” Working Paper, Government of Spain and FEDER (2011): $1-29$.

Ahmad, W., Sehgal, S., and Bhanumurthy, N. "Eurozone Crisis and BRIICKS stock markets: Contagion or market interdependence?"Economic Modelling 33 (2013): 209_ 225.

Ahmad, W., and Sehgal, S. "Regime dependent dynamics and European stock markets: 
Is asset allocation really possible?" Empirica (2014).

Angelini, Paolo, Nobili, Andrea and Picillo, Cristina. "The Interbank Market after August 2007: What Has Changed, and Why?" Journal of Money, Credit and Banking 43(5) (2011): 923-958.

Asongu, S. "Globalization, financial crisis and contagion: time-dynamic evidence from financial markets of developing countries." Journal of Advanced Studies in Finance (2012).

Baele, L., Ferrando, A., Hordahl, P., Krylova, E., and Monnet, C. “ Measuring Financial Integration in the Euro Area." ECB Occassional Paper 14 (2004).

Barro, Robert J., and Xavier Sala-i-Martin. "Convergence.” Journal of Political Economy 100/2 (1992): 223-251.

Bartram, S. M., Taylor, S. J., and Wang, Y.-H. "The Euro and European Financial Market Dependence.” Journal of Banking and Finance 31/5 (2007): 1461-1481.

Baumohl, Eduard. "Stock market integration between the CEE-4 and the G7 markets: Asymmetric DCC and smooth transition approach.” MPRA Paper No. 43834 (2013).

Battistini, N, M Pagano, und S Simonelli. "Systemic risk and home bias in the euro area.” European Commission Economic Papers 494 (2013).

Black, F. "Studies of Stock Price Volatility Changes." In Proceedings of the 1976 American Statistical Association, Business and Economical Statistics Section. Alexandria, VA: American Statistical Association (1976): 177-181.

Brock, W. A., Hsieh, D. A., \& LeBaron, B., Nonlinear dynamics, chaos, and instability: Statistical theory and economic evidence (Cambridge, MA, USA: MIT Press, 1991).

Brock, W. A., Dechert, W. D., LeBaron, B., and Scheinkman, J. A. “A test for independence based on the correlation dimension." Econometric Reviews 15 (1996): 197-235.

Bekaert, G., Harvey, C.R. "Time-varying world market integration.” Journal of Finance 50 (1995): 403-444.

Berben, R.-P., and Jansen, J. W. "Bond Market and Stock Market Integration in Europe." De Nederlandsche Bank Working Paper 60 (2005): 1-37.

Bootle, R., Jessop, J., Kenningham, A., Loynes, J., May, B., McKeown, J., and Pragnell, M. "Leaving the Euro: A Practical Guide." Research Paper, Capital Economics Limited 
(2012). Accessed 22 April 2014. https://www.capitaleconomics.com/wp-content/ uploads/2013/01/wolfson-prize-submission.pdf.

Cecchetti, S. G. "Crisis and Responses: The Federal Reserve in the Early Stages of the Financial Crisis." Journal of Economic Perspectives 23(1) (2009): 51-75.

Cappiello, L., Hördahl, P., Kadareja, A., and Manganelli, S. "The Impact of the Euro on Financial Markets.” Working Paper No. 598, European Central Bank (2006): 1-111.

Christiansen, C. "Integration of European bond markets." Journal of Banking and Finance 42 (2014): 191-198.

Cipollini, A., Coakley, J., and Lee, H. "The European sovereign debt market: from integration to segmentation." The European Journal of Finance 21(2) (2015): 111-128.

Featherstone, K. "The Greek Sovereign Debt Crisis and EMU: A Failing State in a Skewed Regime.” JCMS: Journal of Common Market Studies 49/2 (2011): 193-217.

Fung, L. K.P, Tam, C.S., and Yu, I.W. "Assessing the integration of Asia's equity and bond markets.” BIS paper 12, Bank for International Settlements (2008).

Georgoutsos, D. A., and Migiakis, P. M. "European Sovereign Bond Spreads: Monetray Unification, Market Conditions and Financial Integration." Working Paper 115, Economic Research Department-Special Studies Division, Bank of Greece (2010):1-38.

Hamilton J. D. "A new approach to the economic analysis of nonstationary time series and the business cycle." Econometrica 57/2 (1989): 357-384.

Hamilton, J.D., and Gang, Lin "Stock Market Volatility and the Business Cycle." Journal of Applied Econometrics 11(5) (1996): 573-93.

Johansen, S. "Estimation and Hypothesis Testing of Cointegration Vectors in Gaussian Vector Autoregressive Models.” Econometrica 59/6 (1991): 1551-1580.

Katsimi, M., and Moutos, T. "EMU and the Greek crisis: The political-economy perspective.” European Journal of Political Economy 26/4 (2010): 568-576.

Jorion, Philippe and Schwartz, Eduardo. "Integration vs. Segmentation in the Canadian Stock Market." Journal of Finance 41/3 (1986): 603-14.

Kim, S.-J., Lucey, B. M., and Wu, E. "Dynamics of bond market integration between established and accession European Union countries.” International Financial Markets, Institutions and Money 16 (2006a): 41-56. 
Kim, S.-J., Moshirian, F., and Wu, E. "Evolution of International Stock and Bond Market Integration: Influence of the European Monetary Union.” Journal of Banking and Finance 30/5 (2006b): 1507-1534.

Lamedica, N., and Reno, R. "Integration of international bond markets: did anything change with EMU?.” Applied Economics Letters 14 (2007): 829-832.

Maheu, J., McCurdy, T., and Song, Y. "Components of bull and bear markets: bull corrections and bear rallies." Working Paper, University of Toronto. (2010).

Mankiw, N. G., D. Romer and D. N. Weil.” A Contribution to the Empirics of Economic Growth." Quarterly Journal of Economics 107 (1992): 407-437.

Markowitz, H. "Portfolio Selection.” The Journal of Finance 7/1 (1952): 77-91.

Nelson, D.B. " Conditional Heteroskedasticity in Asset Returns: A New Approach." Econometrica 59/2 (1991): 347-370.

Panagiotidis, T. "Testing the assumption of Linearity." Economics Bulletin 3 (29) (2002): $1-9$.

Pappas, V., Ingham, H., and Marwan, I. "Financial Markets Synchronization and Contagion: Evidence from CEE and Eurozone." Working Paper, University of Lancaster (2013). Accessed 22 December 2013. http://core.ac.uk/download/pdf/9666927.pdf.

Perron, P. "Further Evidence on Breaking Trend Functions in Macroeconomic Variables." Journal of Econometrics 80 (1997): 355-385.

Pozzi, L., and Wolswijk, G. "The time-varying integration of euro area government bond markets." European Economic Review 56 (2012): 36-53.

Sehgal, S., Gupta, P., and Deisting, F. “Assessing Stock Market Integration in EMU economies for Normal and Crisis Periods." Working Paper, Department of Financial Studies, University of Delhi (2014). http://mpra.ub.uni-muenchen.de/64078/1/MPRA paper_64078.pdf.

Serletis, A. and M. King. "Common Stochastic Trends and Convergence of European Union Stock Markets." Manchester School 65/1 (1997): 44-57.

Skintzi, V. D., and Refenes, A. N. "Volatility spillovers and dynamic correlation in European bond markets." International Financial Markets, Institutions and Money 16 (2006): 23-4. 


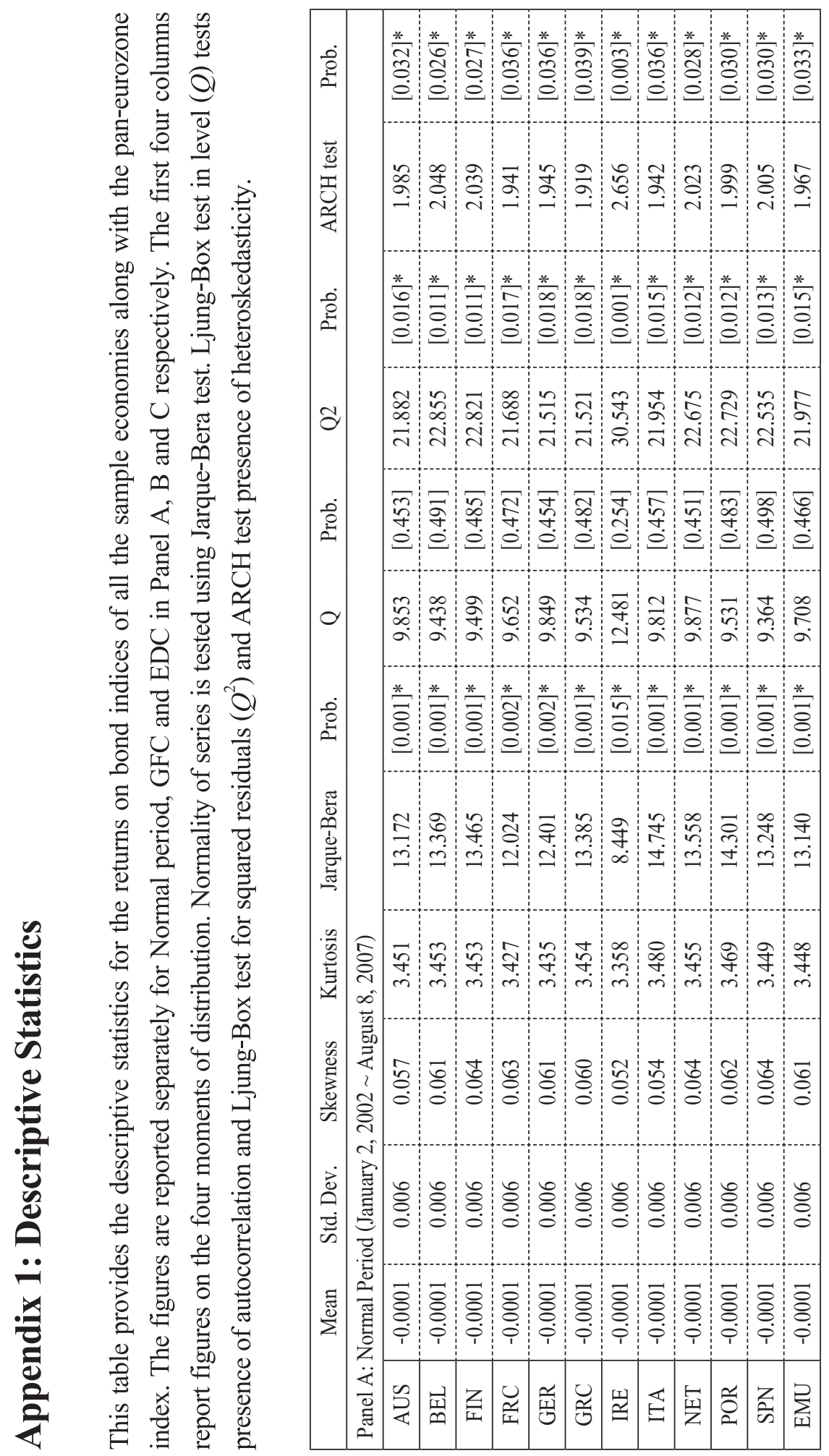


总

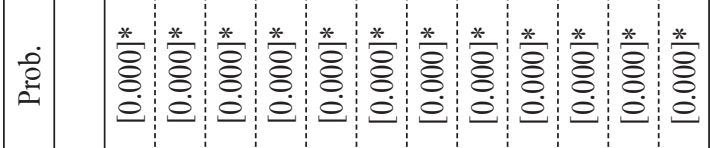

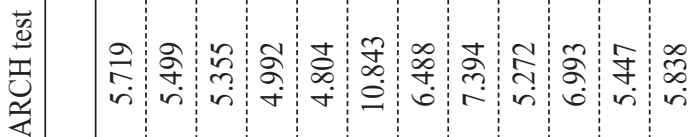

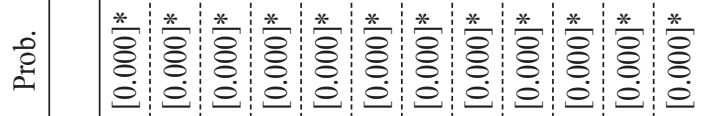
๘

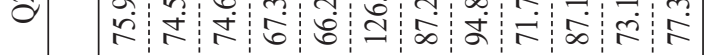

i்

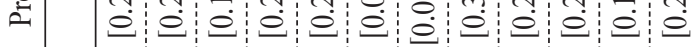
J

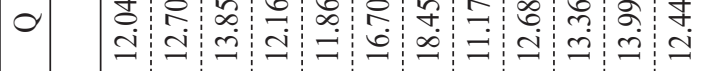

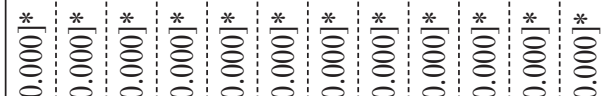

范

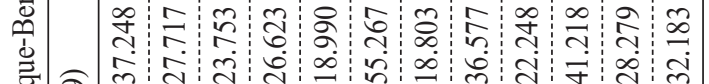
产

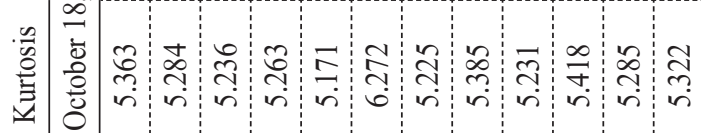

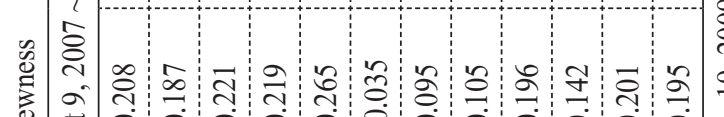
㟶

它

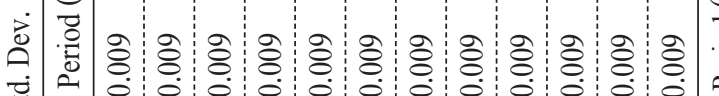

离

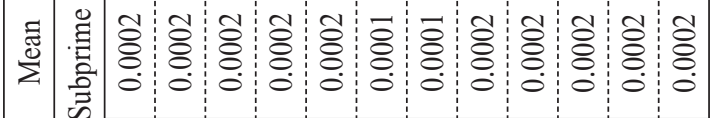

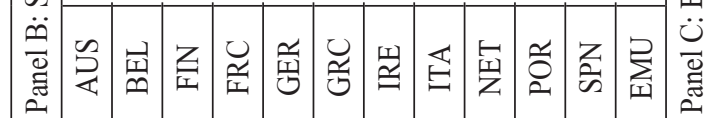

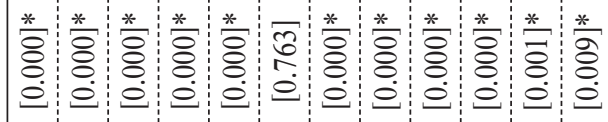

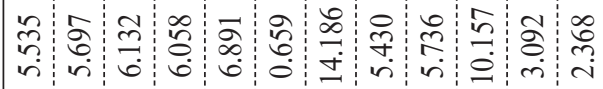

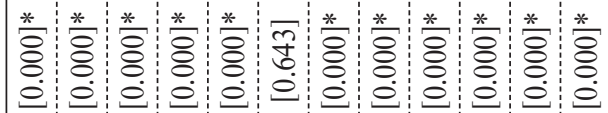

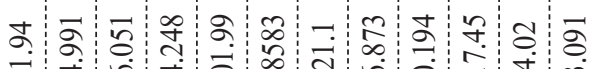

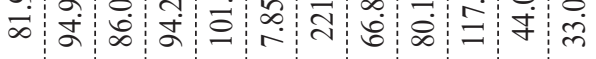

究 ๖

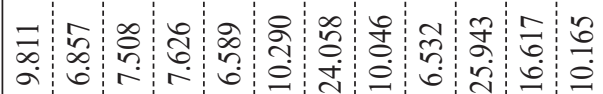

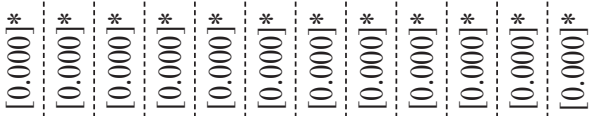

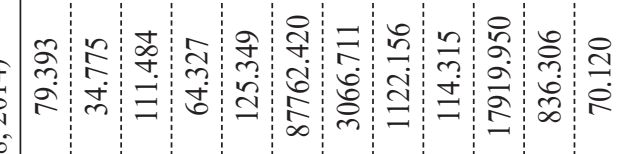

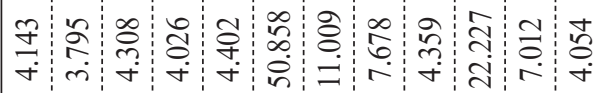

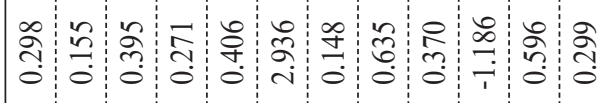

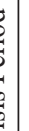

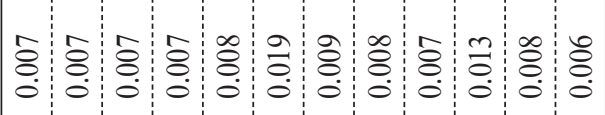

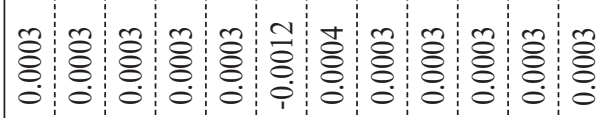

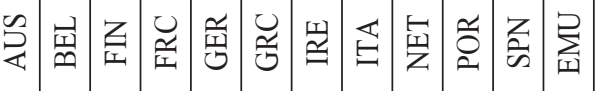

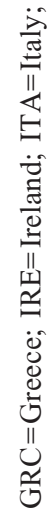

產

푼

ชู.

III

采

这

药

至

厌

㭉芯

क)

iII

至

莺言

क

in $\prod_{0} z$

ठै

氖

을 융

तै 20 वे 焉 के

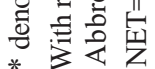
Э尽: 


\section{Appendix 2: Unit Root Tests}

\begin{tabular}{|c|c|c|c|c|c|c|c|}
\hline & \multicolumn{5}{|c|}{ ADF } & \multicolumn{3}{c|}{ Perron (1997) } \\
\hline & \multicolumn{2}{|c|}{ Level } & \multicolumn{1}{c|}{ First Difference } & A & B & C \\
\hline AUS & -2.088 & {$[0.552]$} & -55.762 & {$[0.000]^{*}$} & -3.28 & -3.46 & -2.94 \\
\hline BEL & -1.966 & {$[0.619]$} & -55.641 & {$[0.000]^{*}$} & -3.72 & -3.33 & -2.87 \\
\hline FIN & -2.139 & {$[0.523]$} & -55.876 & {$[0.000]^{*}$} & -3.38 & -3.53 & -2.82 \\
\hline FRC & -2.137 & {$[0.525]$} & -56.542 & {$[0.000]^{*}$} & -3.23 & -3.70 & -2.95 \\
\hline GER & -2.193 & {$[0.493]$} & -55.656 & {$[0.000]^{*}$} & -3.34 & -3.64 & -2.82 \\
\hline GRC & 0.173 & {$[0.971]$} & -48.642 & {$[0.000]^{*}$} & -4.67 & -3.31 & -1.04 \\
\hline IRE & -1.535 & {$[0.818]$} & -28.815 & {$[0.000]^{*}$} & -4.91 & -4.40 & -2.97 \\
\hline ITA & -2.080 & {$[0.556]$} & -56.980 & {$[0.000]^{*}$} & -3.50 & -3.67 & -3.14 \\
\hline NET & -2.160 & {$[0.511]$} & -55.971 & {$[0.000]^{*}$} & -3.40 & -3.56 & -2.84 \\
\hline POR & -1.338 & {$[0.614]$} & -49.402 & {$[0.000]^{*}$} & -3.99 & -4.84 & -3.99 \\
\hline SPN & -2.009 & {$[0.596]$} & -55.521 & {$[0.000]^{*}$} & -3.20 & -3.57 & -3.16 \\
\hdashline EMU & -2.176 & {$[0.502]$} & -57.021 & {$[0.000]^{*}$} & -3.16 & -3.70 & -3.01 \\
\hline
\end{tabular}

(Notes) (i) Perron (1997) unit root test with an endogenously determined breakpoint.

(ii) A, B, C denote the three model types for break in trend, intercept and both respectively.

(iii) The $5 \%$ critical values are $-5.23,-5.59$ and -4.83 for models $\mathrm{A}, \mathrm{B}$ and $\mathrm{C}$, respectively.

(iv) The critical values for ADF are provided by MacKinnon (1996) 5\% critical value -3.412891.

(v) With reference to foot note 5 .

(vi) Abbreviations are as follows $\mathrm{AUS}=$ Austria; $\mathrm{BEL}=$ Belgium; $\mathrm{FIN}=$ Finland; $\mathrm{FRC}=\mathrm{France}$; $\mathrm{GER}=$ Germany; GRC $=$ Greece; IRE $=$ Ireland; ITA=Italy; NET=Netherlands; POR=Portugal; $\mathrm{SPN}=$ Spain; EMU=Europena Economic and Monetary Union. 


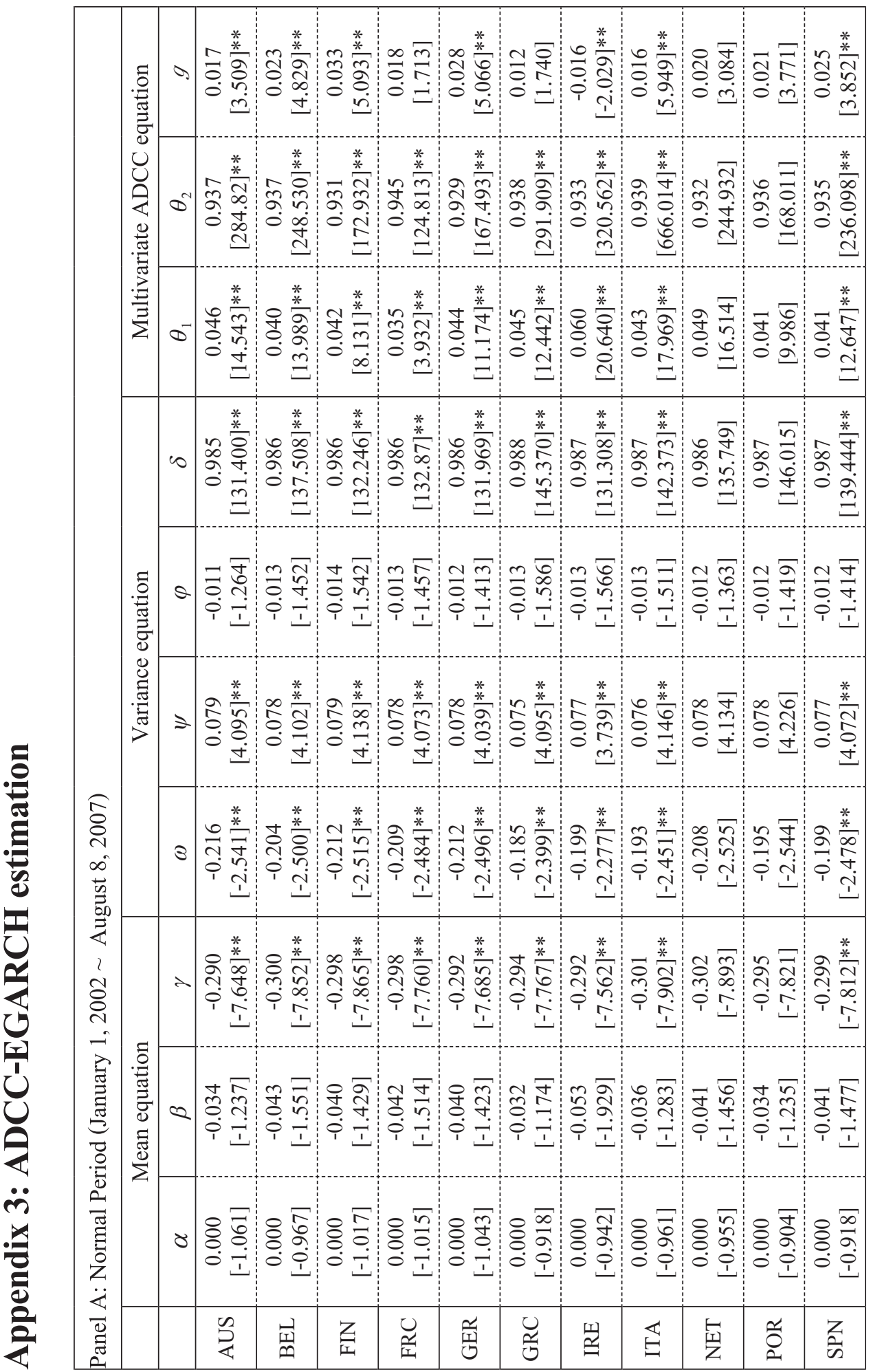


总

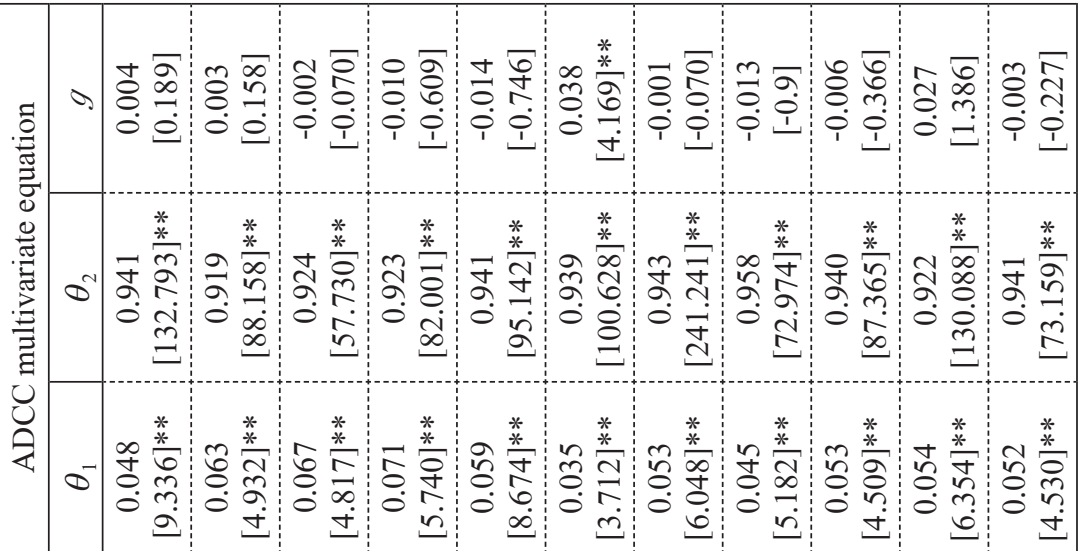

w

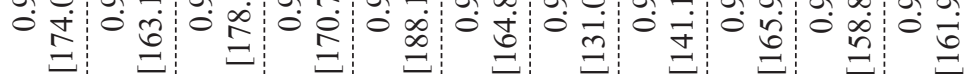

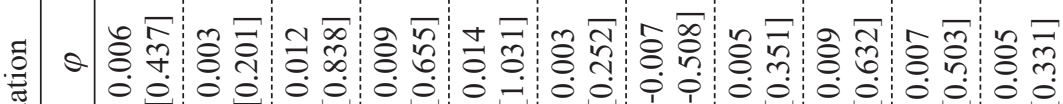
承

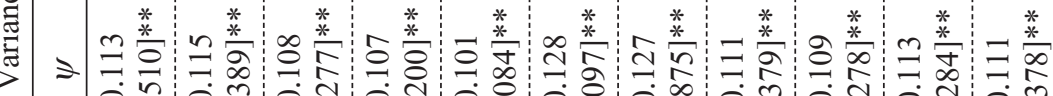

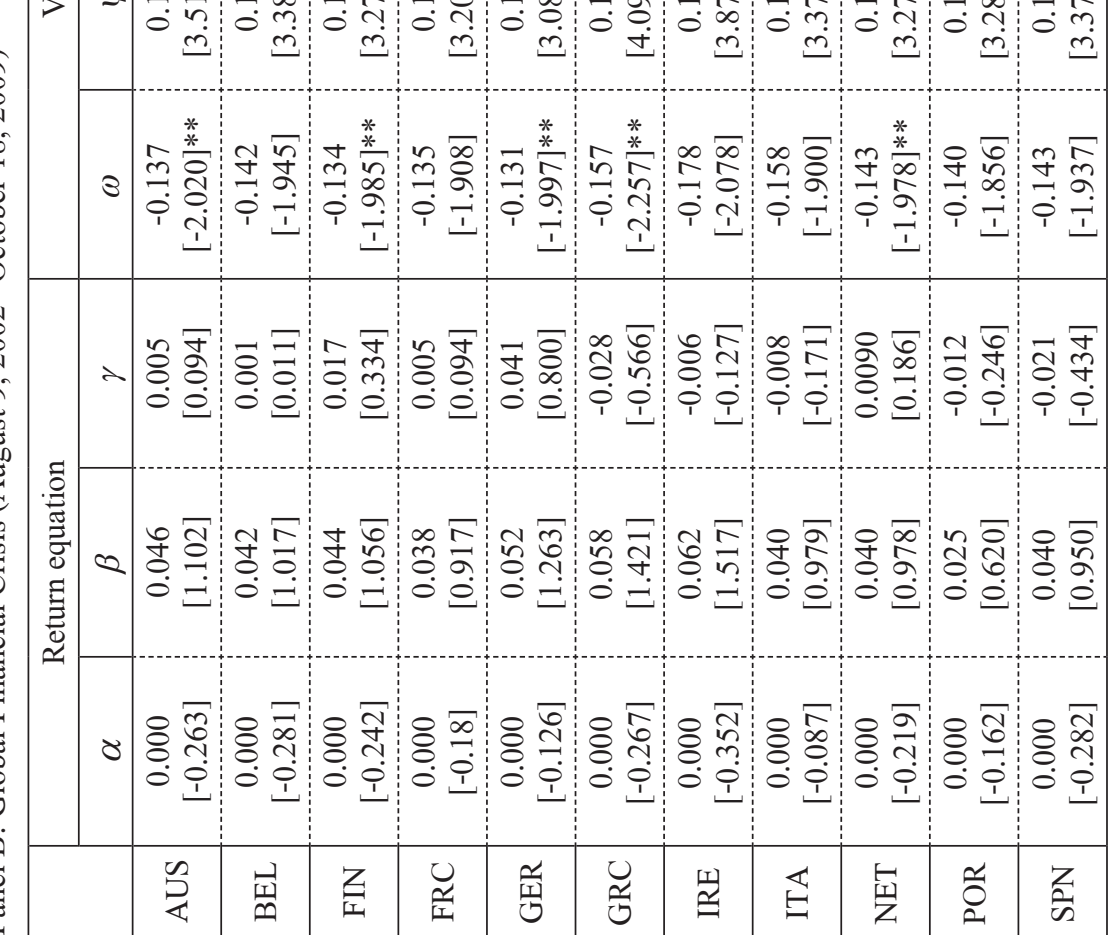


•

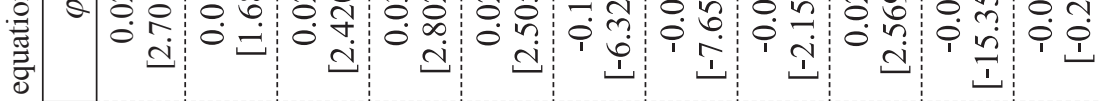

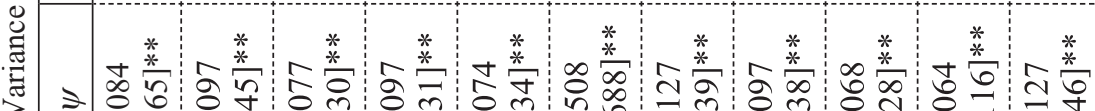

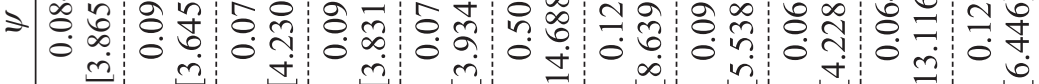

\begin{tabular}{|c|c|c|c|c|c|c|c|c|c|c|c|c|}
\hline & & - & - & 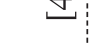 & - & w & 二 & - & 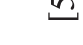 & - & $\beth$ & - \\
\hline & 3 & 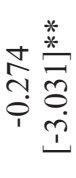 & 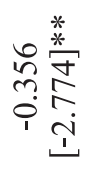 & 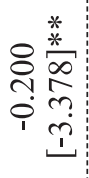 & 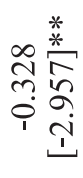 & 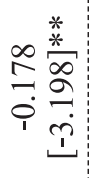 & 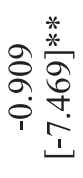 & 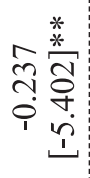 & 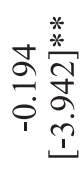 & 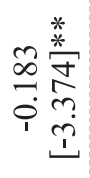 & 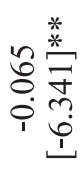 & 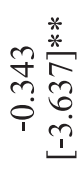 \\
\hline \multirow{3}{*}{ 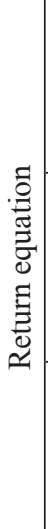 } & $\lambda$ & 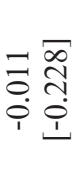 & $\begin{array}{l}0 \\
0 \\
0 \\
0 \\
0 \\
1\end{array}$ & 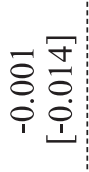 & 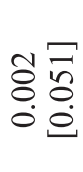 & 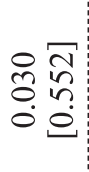 & 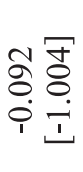 & 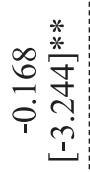 & $\begin{array}{l}0 \\
0 \\
0 \\
0 \\
0 \\
0 \\
1\end{array}$ & 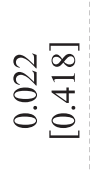 & 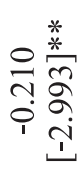 & 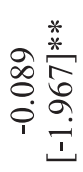 \\
\hline & $Q$ & 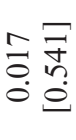 & 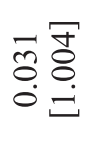 & $\begin{array}{l}2 \pi \\
2.0 \\
0.0\end{array}$ & 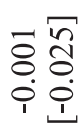 & 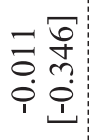 & 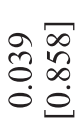 & 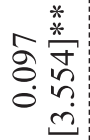 & 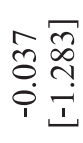 & 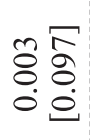 & $\begin{array}{l}\frac{*}{*} \\
\stackrel{*}{\sigma} \\
\stackrel{*}{0} \\
\stackrel{0}{0}\end{array}$ & $\begin{array}{l}0 \sqrt{n} \\
0 \tilde{n} \\
0 \\
0\end{array}$ \\
\hline & 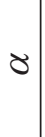 & 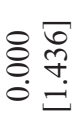 & 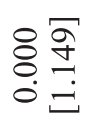 & 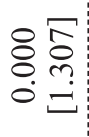 & 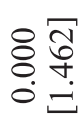 & $\begin{array}{l}82 \\
8 \stackrel{2}{\circ} \\
0\end{array}$ & 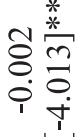 & 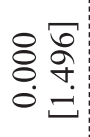 & $\begin{array}{l}0 \\
8 \\
0 \\
0 \\
0 \\
0\end{array}$ & 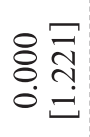 & $\begin{array}{l}\bar{\sigma} \\
8 \overline{0} \\
0 \\
0\end{array}$ & 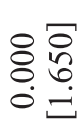 \\
\hline & & 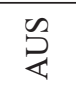 & $\overrightarrow{|r| r}$ & 党 & $\begin{array}{l}U \\
\stackrel{\sim}{I}\end{array}$ & $\frac{\underline{r}}{\mathbb{T}}$ & 芯 & 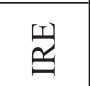 & 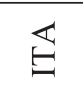 & 苫 & 잉 & $\frac{Z}{\sim}$ \\
\hline
\end{tabular}
政 


\section{Appendix 4: BDS Test of Independence}

This table reports the results for BDS test of independence conducted as a pre-cursor to Markov Switching Model.

\begin{tabular}{|c|c|c|c|c|c|c|c|c|c|}
\hline$\varepsilon / \sigma$ & & \multicolumn{2}{|c|}{0.5} & \multicolumn{2}{|c|}{1} & \multicolumn{2}{|c|}{1.5} & \multicolumn{2}{|c|}{2} \\
\hline $\mathbf{m}$ & & $\begin{array}{l}\text { BDS } \\
\text { Statistic }\end{array}$ & Prob. & $\begin{array}{l}\text { BDS } \\
\text { Statistic }\end{array}$ & Prob. & $\begin{array}{l}\text { BDS } \\
\text { Statistic }\end{array}$ & Prob. & $\begin{array}{l}\text { BDS } \\
\text { Statistic }\end{array}$ & Prob. \\
\hline \multicolumn{10}{|l|}{ AUS } \\
\hline & 2 & 0.003 & {$[0.002]^{*}$} & 0.004 & {$[0.003]^{*}$} & 0.005 & {$[0.003]^{*}$} & 0.005 & {$[0.002]^{*}$} \\
\hline & 3 & 0.004 & {$[0.002]^{*}$} & 0.008 & {$[0.004]^{*}$} & 0.012 & {$[0.005]^{*}$} & 0.014 & {$[0.004]^{*}$} \\
\hline & 4 & 0.004 & {$[0.002]^{*}$} & 0.009 & {$[0.004]^{*}$} & 0.019 & {$[0.006]^{*}$} & 0.025 & {$[0.006]^{*}$} \\
\hline & 5 & 0.003 & {$[0.001]^{*}$} & 0.010 & {$[0.003]^{*}$} & 0.026 & {$[0.007]^{*}$} & 0.037 & {$[0.007]^{*}$} \\
\hline & 6 & 0.002 & {$[0.001]^{*}$} & 0.009 & {$[0.002]^{*}$} & 0.031 & {$[0.007]^{*}$} & 0.048 & {$[0.009]^{*}$} \\
\hline \multicolumn{10}{|l|}{ BEL } \\
\hline & 2 & 0.003 & {$[0.001]^{*}$} & 0.007 & {$[0.003]^{*}$} & 0.008 & {$[0.003]^{*}$} & 0.007 & {$[0.002]^{*}$} \\
\hline & 3 & 0.002 & {$[0.001]^{*}$} & 0.011 & {$[0.00$} & 0.019 & {$[0.005]^{*}$} & 0.019 & {$[0.004]^{*}$} \\
\hline & 4 & 0.001 & {$[0.000]^{*}$} & 0.013 & {$[0.003]^{*}$} & 0.028 & {$[0.006]^{*}$} & 0.033 & {$[0.006]^{*}$} \\
\hline & 5 & 0.001 & {$[0.000]^{*}$} & 0.014 & {$[0.003]^{*}$} & 0.036 & {$[0.007]^{*}$} & 0.047 & {$[0.007]^{*}$} \\
\hline & 6 & 0.000 & {$[0.000]^{*}$} & 0.012 & {$[0.0$} & 0.040 & {$[0.00$} & 0.058 & {$[0.008]^{*}$} \\
\hline \multicolumn{10}{|l|}{ FIN } \\
\hline & 2 & 0.002 & {$[0.001]^{*}$} & 0.004 & {$[0.003] *$} & 0.004 & {$[0.003] *$} & 0.004 & {$[0.002]^{*}$} \\
\hline & 3 & 0.001 & {$[0.001]^{*}$} & 0.007 & {$[0.004]^{*}$} & 0.010 & {$[0.005]^{*}$} & 0.012 & {$[0.004]^{*}$} \\
\hline & 4 & 0.001 & {$[0]^{*}$} & 0.010 & {$[0.004]^{*}$} & 0.019 & {$[0.006]^{*}$} & 0.023 & {$[0.006]^{*}$} \\
\hline & 5 & 0.001 & [0]* & 0.012 & {$[0.003]^{*}$} & 0.029 & {$[0.007]^{*}$} & 0.038 & {$[0.007]^{*}$} \\
\hline & 6 & 0.000 & {$[0]^{*}$} & 0.011 & {$[0.002]^{*}$} & 0.035 & {$[0.007]^{*}$} & 0.050 & {$[0.009]^{*}$} \\
\hline \multicolumn{10}{|l|}{ FRC } \\
\hline & 2 & 0.002 & {$[0.001]^{*}$} & 0.004 & {$[0.003]^{*}$} & 0.004 & {$[0.003]^{*}$} & 0.004 & {$[0.002]^{*}$} \\
\hline & 3 & 0.001 & {$[0.001]^{*}$} & 0.008 & {$[0.004]^{*}$} & 0.012 & {$[0.005]^{*}$} & 0.013 & {$[0.004]^{*}$} \\
\hline & 4 & 0.001 & {$[0.000]^{*}$} & 0.010 & {$[0.004]^{*}$} & 0.020 & {$[0.006]^{*}$} & 0.024 & {$[0.006]^{*}$} \\
\hline & 5 & 0.001 & {$[0.000]^{*}$} & 0.011 & {$[0.003]^{*}$} & 0.029 & {$[0.007]^{*}$} & 0.037 & {$[0.007]^{*}$} \\
\hline & 6 & 0.000 & {$[0.000]^{*}$} & 0.010 & {$[0.002]^{*}$} & 0.034 & {$[0.007]^{*}$} & 0.049 & {$[0.009]^{*}$} \\
\hline
\end{tabular}


(continued)

\begin{tabular}{|c|c|c|c|c|c|c|c|c|c|}
\hline \multirow{2}{*}{$\frac{\varepsilon / \sigma}{\mathbf{m}}$} & \multicolumn{3}{|c|}{0.5} & \multicolumn{2}{|c|}{1} & \multicolumn{2}{|c|}{1.5} & \multicolumn{2}{|c|}{2} \\
\hline & & $\begin{array}{l}\text { BDS } \\
\text { Statistic }\end{array}$ & Prob. & $\begin{array}{l}\text { BDS } \\
\text { Statistic }\end{array}$ & Prob. & $\begin{array}{l}\text { BDS } \\
\text { Statistic }\end{array}$ & Prob. & $\begin{array}{l}\text { BDS } \\
\text { Statistic }\end{array}$ & Prob. \\
\hline \multicolumn{10}{|l|}{ GER } \\
\hline & 2 & 0.002 & {$[0.001]^{*}$} & 0.005 & {$[0.003]^{*}$} & 0.005 & {$[0.003]^{*}$} & 0.004 & {$[0.002]^{*}$} \\
\hline & 3 & 0.001 & {$[0.001]^{*}$} & 0.008 & {$[0.004]^{*}$} & 0.011 & {$[0.005]^{*}$} & 0.012 & {$[0.004]^{*}$} \\
\hline & 4 & 0.001 & {$[0.000]^{*}$} & 0.011 & {$[0.003]^{*}$} & 0.021 & {$[0.006]^{*}$} & 0.024 & {$[0.006]^{*}$} \\
\hline & 5 & 0.001 & {$[0.000]^{*}$} & 0.013 & {$[0.003]^{*}$} & 0.031 & {$[0.007]^{*}$} & 0.039 & {$[0.007]^{*}$} \\
\hline & 6 & 0.000 & {$[0.000]^{*}$} & 0.012 & {$[0.002]^{*}$} & 0.038 & {$[0.007]^{*}$} & 0.052 & {$[0.009]^{*}$} \\
\hline \multicolumn{10}{|l|}{ GRC } \\
\hline & 2 & 0.018 & {$[0.003]^{*}$} & 0.035 & {$[0.005]^{*}$} & 0.027 & {$[0.004]^{*}$} & 0.014 & {$[0.003]^{*}$} \\
\hline & 3 & 0.023 & {$[0.003]^{*}$} & 0.073 & {$[0.008]^{*}$} & 0.066 & {$[0.007]^{*}$} & 0.040 & {$[0.006]^{*}$} \\
\hline & 4 & 0.020 & {$[0.003]^{*}$} & 0.097 & {$[0.009]^{*}$} & 0.098 & {$[0.01]^{*}$} & 0.062 & {$[0.009]^{*}$} \\
\hline & 5 & 0.015 & {$[0.002]^{*}$} & 0.110 & {$[0.01]^{*}$} & 0.125 & {$[0.013]^{*}$} & 0.086 & {$[0.012] *$} \\
\hline & 6 & 0.011 & {$[0.001]^{*}$} & 0.121 & {$[0.01]^{*}$} & 0.155 & {$[0.014]^{*}$} & 0.112 & {$[0.014]^{*}$} \\
\hline \multicolumn{10}{|l|}{ IRE } \\
\hline & 2 & 0.009 & {$[0.002]^{*}$} & 0.027 & {$[0.004]^{*}$} & 0.033 & {$[0.003]^{*}$} & 0.027 & {$[0.003]^{*}$} \\
\hline & 3 & 0.008 & {$[0.002]^{*}$} & 0.041 & {$[0.005]^{*}$} & 0.062 & {$[0.006]^{*}$} & 0.055 & {$[0.005]^{*}$} \\
\hline & 4 & 0.006 & {$[0.001]^{*}$} & 0.047 & {$[0.006]^{*}$} & 0.085 & {$[0.008]^{*}$} & 0.081 & {$[0.007]^{*}$} \\
\hline & 5 & 0.003 & {$[0.001]^{*}$} & 0.047 & {$[0.005]^{*}$} & 0.102 & {$[0.009]^{*}$} & 0.106 & {$[0.009]^{*}$} \\
\hline & 6 & 0.002 & {$[0.000]^{*}$} & 0.043 & {$[0.004]^{*}$} & 0.115 & {$[0.010]^{*}$} & 0.131 & {$[0.011]^{*}$} \\
\hline \multicolumn{10}{|l|}{ ITA } \\
\hline & 2 & 0.002 & {$[0.001] *$} & 0.005 & {$[0.003]^{*}$} & 0.007 & {$[0.003]^{*}$} & 0.006 & {$[0.002]^{*}$} \\
\hline & 3 & 0.002 & {$[0.001]^{*}$} & 0.009 & {$[0.004]^{*}$} & 0.015 & {$[0.005]^{*}$} & 0.015 & {$[0.004]^{*}$} \\
\hline & 4 & 0.001 & {$[0.000]^{*}$} & 0.012 & {$[0.003]^{*}$} & 0.025 & {$[0.006]^{*}$} & 0.027 & {$[0.006]^{*}$} \\
\hline & 5 & 0.001 & {$[0.000]^{*}$} & 0.012 & {$[0.003]^{*}$} & 0.033 & {$[0.007]^{*}$} & 0.042 & {$[0.007]^{*}$} \\
\hline & 6 & 0.000 & {$[0.000]^{*}$} & 0.011 & {$[0.002]^{*}$} & 0.037 & {$[0.007]^{*}$} & 0.053 & {$[0.008]^{*}$} \\
\hline \multicolumn{10}{|l|}{ NET } \\
\hline & 2 & 0.001 & {$[0.001] *$} & 0.003 & {$[0.003]^{*}$} & 0.004 & {$[0.003]^{*}$} & 0.004 & {$[0.002]^{*}$} \\
\hline & 3 & 0.001 & {$[0.001]^{*}$} & 0.006 & {$[0.004]^{*}$} & 0.010 & {$[0.005]^{*}$} & 0.012 & {$[0.004]^{*}$} \\
\hline & 4 & 0.001 & {$[0.000]^{*}$} & 0.009 & {$[0.003]^{*}$} & 0.019 & {$[0.006]^{*}$} & 0.023 & {$[0.006]^{*}$} \\
\hline & 5 & 0.001 & {$[0.000]^{*}$} & 0.011 & {$[0.003]^{*}$} & 0.028 & {$[0.007]^{*}$} & 0.038 & {$[0.007]^{*}$} \\
\hline & 6 & 0.000 & {$[0.000]^{*}$} & 0.011 & {$[0.002]^{*}$} & 0.034 & {$[0.007]^{*}$} & 0.050 & {$[0.009]^{*}$} \\
\hline
\end{tabular}


(continued)

\begin{tabular}{|c|c|c|c|c|c|c|c|c|c|}
\hline$\varepsilon / \sigma$ & \multicolumn{3}{|c|}{0.5} & \multicolumn{2}{|c|}{1} & \multicolumn{2}{|c|}{1.5} & \multicolumn{2}{|c|}{2} \\
\hline m & & $\begin{array}{l}\text { BDS } \\
\text { Statistic }\end{array}$ & Prob. & $\begin{array}{l}\text { BDS } \\
\text { Statistic }\end{array}$ & Prob. & $\begin{array}{l}\text { BDS } \\
\text { Statistic }\end{array}$ & Prob. & $\begin{array}{l}\text { BDS } \\
\text { Statistic }\end{array}$ & Prob. \\
\hline \multicolumn{10}{|l|}{ POR } \\
\hline & 2 & 0.012 & {$[0.002] *$} & 0.027 & {$[0.004]^{*}$} & 0.025 & {$[0.004]^{*}$} & 0.015 & {$[0.002]^{*}$} \\
\hline & 3 & 0.015 & {$[0.002]^{*}$} & 0.053 & {$[0.006]^{*}$} & 0.059 & {$[0.006]^{*}$} & 0.039 & {$[0.005]^{*}$} \\
\hline & 4 & 0.011 & {$[0.001]^{*}$} & 0.069 & {$[0.007]^{*}$} & 0.092 & {$[0.008]^{*}$} & 0.067 & {$[0.007]^{*}$} \\
\hline & 5 & 0.007 & {$[0.001]^{*}$} & 0.073 & {$[0.006]^{*}$} & 0.120 & {$[0.01]^{*}$} & 0.094 & [0.009]* \\
\hline & 6 & 0.004 & {$[0.000]^{*}$} & 0.072 & {$[0.006]^{*}$} & 0.142 & {$[0.011]^{*}$} & 0.121 & {$[0.011]^{*}$} \\
\hline \multicolumn{10}{|l|}{ SPN } \\
\hline & 2 & 0.002 & {$[0.001]^{*}$} & 0.003 & {$[0.003]^{*}$} & 0.005 & {$[0.003]^{*}$} & 0.005 & {$[0.002]^{*}$} \\
\hline & 3 & 0.001 & {$[0.001]^{*}$} & 0.006 & {$[0.004]^{*}$} & 0.011 & {$[0.005]^{*}$} & 0.012 & {$[0.004]^{*}$} \\
\hline & 4 & 0.001 & {$[0.000]^{*}$} & 0.009 & {$[0.003]^{*}$} & 0.019 & {$[0.006]^{*}$} & 0.023 & {$[0.006]^{*}$} \\
\hline & 5 & 0.000 & {$[0.000]^{*}$} & 0.010 & {$[0.003]^{*}$} & 0.028 & {$[0.007]^{*}$} & 0.036 & {$[0.007]^{*}$} \\
\hline & 6 & 0.000 & {$[0.000]^{*}$} & 0.009 & {$[0.002]^{*}$} & 0.032 & {$[0.007]^{*}$} & 0.047 & [0.008]* \\
\hline \multicolumn{10}{|l|}{ EMU } \\
\hline & 2 & 0.001 & {$[0.001]^{*}$} & 0.004 & {$[0.003]^{*}$} & 0.006 & {$[0.003]^{*}$} & 0.007 & {$[0.002]^{*}$} \\
\hline & 3 & 0.001 & {$[0.001]^{*}$} & 0.006 & {$[0.004]^{*}$} & 0.013 & {$[0.005]^{*}$} & 0.016 & {$[0.004]^{*}$} \\
\hline & 4 & 0.000 & {$[0.000]^{*}$} & 0.008 & {$[0.004]^{*}$} & 0.020 & {$[0.006]^{*}$} & 0.027 & {$[0.006]^{*}$} \\
\hline & 5 & 0.000 & {$[0.000] *$} & 0.008 & {$[0.003]^{*}$} & 0.026 & {$[0.007]^{*}$} & 0.040 & {$[0.007]^{*}$} \\
\hline & 6 & 0.000 & {$[0.000]^{*}$} & 0.008 & {$[0.002]^{*}$} & 0.030 & {$[0.007]^{*}$} & 0.050 & {$[0.009]^{*}$} \\
\hline
\end{tabular}

(Notes) (i) * indicates significant at 5\% critical level, $m$ indicates for embedding dimensions, $\varepsilon$ is the distance measured in terms of the number of standard deviations of the data.

(ii) With reference to foot note 12 .

(iii) Abbreviations are as follows $\mathrm{AUS}=$ Austria; $\mathrm{BEL}=$ Belgium; $\mathrm{FIN}=$ Finland; $\mathrm{FRC}=$ France; $\mathrm{GER}=$ Germany; GRC=Greece; IRE=Ireland; ITA=Italy; NET=Netherlands; POR=Portugal; SPN=Spain; EMU $=$ Europena Economic and Monetary Union. 


\section{Appendix 5}

The Principal Component Analysis (PCA) was conducted to extract factors from the bond returns series of sample economies. These factors (statistical factors) were then employed in the rolling regression analysis, wherein for each sample country, the bond returns were regressed on these factors in order to check the robustness of the common factors model. This was done by comparing the average Adjusted Square values obtained from both regressions. Furthermore, we attempted to identify the statistical factors with the a priori common factors with the help of auxiliary regressions.

Panel A reports the eigenvalues and proportion of variance explained for the two factors extracted from the PCA. Panel B shows the factor loadings for each sample country. Variable denotes the bond returns series for each sample country.

Panel C reports the results of auxiliary regressions. The results show that Statistical Factor 1 can be identified as EMU Bond Returns given the significant coefficient and sound value of the Adjusted $R$-square. However, the Statistical Factor 2 cannot clearly be identified with any single common factor.

\begin{tabular}{|c|c|c|}
\hline \multicolumn{2}{|c|}{ Panel A: Principal Component Analysis: the components (statistical Factors) extracted } \\
\hline Factor Number & Eigenvalue & Proportion of total variance explained \\
\hline 1 & 8.894298 & 0.8086 \\
\hline 2 & 1.026736 & 0.0933 \\
\hline Panel B: Principal Component Analysis: the factor loadings \\
\hline Variable & Statistical factor 1 & Statistical factor 2 \\
\hline Austria & 0.32653 & -0.17451 \\
\hline Belgium & 0.326072 & -0.09353 \\
\hline Finland & 0.324135 & -0.20286 \\
\hline France & 0.326549 & -0.17758 \\
\hline Germany & 0.319409 & -0.22912 \\
\hline Greece & 0.178161 & 0.716757 \\
\hline Ireland & 0.283556 & 0.280195 \\
\hline Italy & 0.311057 & 0.051187 \\
\hline Netherlands & 0.324451 & -0.19917 \\
\hline Portugal & 0.244259 & 0.445075 \\
\hline Spain & 0.31544 & 0.054657 \\
\hline
\end{tabular}


(continued)

\begin{tabular}{|c|c|c|c|}
\hline \multicolumn{4}{|c|}{$\begin{array}{l}\text { Panel C: Auxiliary Regression for the purpose of identifying the statistical factors with a } \\
\text { priori factors }\end{array}$} \\
\hline \multicolumn{2}{|c|}{ Statistical factor 1} & \multicolumn{2}{|c|}{ Statistical factor 2} \\
\hline \multicolumn{2}{|c|}{ Regression on EMU Bond Returns } & \multicolumn{2}{|c|}{ Regression on EMU Bond Returns } \\
\hline$\alpha$ & $\beta$ & $\alpha$ & $\beta$ \\
\hline-0.00716 & 147.686 & 0.000316 & -6.51132 \\
\hline$[-4.343]^{*}$ & {$[603.83] *$} & {$[0.017]$} & {$[-2.357]^{*}$} \\
\hline Adjusted $R$-squared & 0.992174 & Adjusted $R$-squared & 0.0016 \\
\hline \multicolumn{2}{|c|}{ Regression on Term Spread } & \multicolumn{2}{|c|}{ Regression on Term Spread } \\
\hline$\alpha$ & $\beta$ & $\alpha$ & $\beta$ \\
\hline 0.040455 & -3.4169 & -0.01099 & 0.928454 \\
\hline$[1.32]$ & {$[-1.663]$} & {$[-0.359]$} & {$[0.452]$} \\
\hline Adjusted $R$-squared & 0.000614 & Adjusted $R$-squared & -0.0003 \\
\hline \multicolumn{2}{|c|}{ Regression on Default Spread } & \multicolumn{2}{|c|}{ Regression on Default Spread } \\
\hline$\alpha$ & $\beta$ & $\alpha$ & $\beta$ \\
\hline $1.95 \mathrm{E}-05$ & 1.406702 & 0.000394 & 28.37899 \\
\hline$[0.001]$ & [0.219] & {$[0.021]$} & {$[4.426]^{*}$} \\
\hline Adjusted $R$-squared & -0.00033 & Adjusted $R$-squared & 0.0064 \\
\hline \multicolumn{2}{|c|}{ Regression on Return Differential } & \multicolumn{2}{|c|}{ Regression on Return Differential } \\
\hline$\alpha$ & $\beta$ & $\alpha$ & $\beta$ \\
\hline-0.00476 & 16.20632 & 0.003436 & -11.703 \\
\hline$[-0.265]$ & {$[15.053]^{*}$} & {$[0.188]$} & {$[-10.671] *$} \\
\hline Adjusted $R$-squared & 0.072731 & Adjusted $R$-squared & 0.0378 \\
\hline
\end{tabular}

(Notes) (i) * indicates significant at 5\% critical level.

(ii) With reference to Foot Note 13 and 14. 